Check for updates

Cite this: J. Mater. Chem. B, 2021, 9, 1647

Received 25th November 2020, Accepted 16th January 2021

DOI: $10.1039 / \mathrm{dOtb02757j}$

rsc.li/materials-b

\section{Fibronectin adsorption on oxygen plasma-treated polyurethane surfaces modulates endothelial cell response $\uparrow$}

\author{
Ruben Daum, $\ddagger^{\mathrm{ab}}$ Ivana Mrsic, $\ddagger^{\mathrm{c}}$ Johanna Hutterer, $\mathbb{D}^{\mathrm{c}}$ Achim Junginger, ${ }^{\mathrm{c}}$ \\ Svenja Hinderer, (D) ${ }^{a b}$ Alfred J. Meixner, ${ }^{c d}$ Günter Gauglitz, ${ }^{c}$ Thomas Chassé ${ }^{c d}$ and \\ Katja Schenke-Layland (D) *abef
}

\begin{abstract}
Fibronectin coating increases implant biocompatibility by enhancing surface endothelialization via integrin-mediated binding. Surface properties determine the fibronectin orientation and conformation, dictating which ligands are presented, and therefore altering the bioactivity of an implant surface. In this study, polyurethane was treated with oxygen plasma, which allowed for a simultaneous modification of the surface chemistry and topography to modulate fibronectin adsorption. By varying the parameters of the treatment, human plasma fibronectin adsorbed on the surfaces in different conformations, orientations, and binding affinities, which was investigated by atomic force microscopy, fluorescence microscopy, monoclonal and polyclonal antibody staining and reflectometric interference spectroscopy. Apart from the most hydrophilic rough surfaces, the adsorbed fibronectin showed a lower binding affinity and less conformational change on the more hydrophilic surfaces. A large amount of exposed fibronectin-cell binding was detected on the rough treated and the smooth untreated surfaces. Primary isolated human umbilical vein and human microvascular endothelial cells showed a significantly higher cell adherence on the absorbed fibronectin with a low binding affinity and low conformational changes. Significant differences in the formation of mature focal adhesions and the reorganization of F-actin were identified on the rough treated and the smooth untreated surfaces. Our data suggest that oxygen plasma treatment is a reliable technique for the modulation of fibronectin adsorption in order to adjust fibronectin bioactivity and impact cell responses to implant surfaces.
\end{abstract}

\section{Introduction}

The interaction between cardiovascular implants and cells in the human body is highly influenced by the layer of blood

\footnotetext{
${ }^{a}$ NMI Natural and Medical Sciences, Institute at the University of Tübingen, Markwiesenstr. 55, 72770 Reutlingen, Germany. Web: www.nmi.de/en

${ }^{b}$ Department of Women's Health, Research Institute for Women's Health, Eberhard Karls University Tübingen, Silcherstr. 7/1, 72076 Tübingen, Germany. E-mail: katja.schenke-layland@uni-tuebingen.de; Tel: +49-707-1298-5205; Web: www.schenke-layland-lab.de

${ }^{c}$ Institute of Physical and Theoretical Chemistry, Eberhard Karls University Tübingen, Auf der Morgenstelle 18, 72076 Tübingen, Germany

${ }^{d}$ Center for Light-Matter Interaction, Sensors \& Analytics (LISA+) at the University of Tübingen, Auf der Morgenstelle 18, 72076 Tübingen, Germany

${ }^{e}$ Cluster of Excellence iFIT (EXC 2180) "Image-Guided and Functionally Instructed Tumor Therapies", Eberhard Karls University Tübingen, 72076 Tübingen, Germany ${ }^{f}$ Department of Medicine/Cardiology, Cardiovascular Research Laboratories, David Geffen School of Medicine at UCLA, Los Angeles, CA, 90095, USA

$\dagger$ Electronic supplementary information (ESI) available. See DOI: 10.1039/ dotb02757j

\$ These authors contributed equally to this work.
}

proteins initially adsorbed onto the synthetic material surfaces. ${ }^{1}$ In order to trigger specific reactions in the body, an implant material can be functionalized with bioactive substances. An attractive candidate that has been reported to support endothelialization of the surface is fibronectin (FN), a well-studied glycoprotein of the extracellular matrix (ECM) ${ }^{2-4}$ However, the influence of the surface properties on the deposition and thus bioactivity of FN is often neglected. FN fulfils a wide range of biological functions as it interacts with other ECM molecules and growth factors, binds to cell surface receptors and forms fibrils through intermolecular interactions. ${ }^{5,6}$ It is a $440 \mathrm{kDa}$ macromolecule that is secreted as a dimer connected by two disulfide S-S bonds at the C-terminus. The two peptide chains consist of several repeating domains (FNI, FNII and FNIII) that can associate with each other, resulting in a globular folding structure of FN. ${ }^{7}$ Moreover, FN is very flexible and can change its conformation depending on the environment. ${ }^{8}$ In vivo, $\mathrm{FN}$ is synthesized, for example, by hepatocytes and secreted into the blood plasma in an inactive globular conformation. ${ }^{9}$ The soluble plasma FN 
binds poorly to many cell types. In early wound-healing responses; however, it undergoes conformational changes by interacting with fibrin and platelets. ${ }^{10}$ During this finely tuned unfolding process of the protein, cell- and FN-binding sides are exposed, which leads to further stages of tissue repair. ${ }^{10}$ The folding of FN adsorbed on biomaterial surfaces has been shown to be influenced by surface properties such as wettability, ${ }^{11}$ surface chemistry, ${ }^{12}$ and roughness. ${ }^{13}$ In recent years, several studies have investigated the influence of modified substrates on the conformation of FN and its effect on cell behavior. ${ }^{14-17}$ Based on this knowledge, research now aims to specifically control cell attachment, proliferation, and differentiation through substrate-dependent changes. ${ }^{18-20}$ Cells interact with FN mainly via the $\alpha 5 \beta 1$ integrin, which binds to the RGD loop on FNIII $_{10}$ and the neighboring PHSRN sequence in FNIII $_{9}{ }^{21-23}$ This interaction induces integrin clustering and the formation of focal adhesion complexes. ${ }^{10}$ These protein complexes are dynamic structures that form mechanical links between FN and the cell cytoskeleton, and mediate the transduction of signaling events, which in turn affects the growth, differentiation, adhesion, and motility of the cell. ${ }^{9}$ At the same time, the cell assembles FN into a fibrillar network through an integrindependent mechanism. ${ }^{24}$ All these processes are strongly influenced by the conformation and the adhesive force of the adsorbed FN, and ultimately determine cell behavior. ${ }^{20}$

In this study, we investigated the adsorption behavior of FN and subsequently the endothelial cell-surface interaction through the fine-tuning of the surface wettability with oxygen plasma treatment of polyurethane (PU). The selected material is a commercially available PU of the Pellethane ${ }^{\mathbb{R}}$ series, which is being currently studied in cardiovascular devices. ${ }^{3}$ The effects of oxygen plasma on the wettability of Pellethane ${ }^{\mathbb{R}}$ was examined in a recent study over a wide range of plasma treatment parameters. ${ }^{25}$ Using this method allows the incorporation of oxygen-rich functional groups onto the material surface changing the chemical composition. ${ }^{26}$ Simultaneously to functionalization, the competing plasma etching of low molecular contaminations and upper polymer surface layers is modifying the surface topography and therefore material roughness. ${ }^{27,28}$ The objective of this study was a defined modification of the surface chemistry and roughness of PU in order to modulate the adsorption behavior and conformation of FN, which affects its bioactivity and subsequently influences endothelial cell responses, potentially providing surfaces for various cardiovascular applications.

\section{Materials \& methods}

\subsection{Sample preparation}

2.1.1 Polyurethane spin-coating and oxygen plasma treatment. The commercially available PU Pellethane 2363-55DE (Lubrizol, Wickliffe, OH, USA) was dissolved in dimethylacetamide (99+\% extra pure, Acros Organics, Fair Lawn, NJ, USA) to obtain a $5 \%(\mathrm{w} / \mathrm{w})$ solution. The solution was spin-coated (Convac 1001, Fairchild Semiconductor, Stuttgart, Germany) at
Table 1 Plasma modification parameters of the PU samples

\begin{tabular}{lll}
\hline Sample & Pressure (mbar) & Time (min) \\
\hline A & 0.2 & 3.0 \\
$\mathrm{~B}$ & 0.2 & 0.2 \\
$\mathrm{C}$ & 0.8 & 3.0 \\
$\mathrm{D}$ & 0.5 & 1.6 \\
$\mathrm{E}$ & 0.8 & 0.2 \\
$\mathrm{~F}^{a}$ & - & - \\
${ }^{a}$ Sample F was not plasma treated and served as control.
\end{tabular}

$2400 \mathrm{rpm}$ for 40 seconds onto heated pre-cut silicon wafers (Siegert Wafer, Aachen, Germany) and glass slides, resulting in film thicknesses ranging between 270 and $300 \mathrm{~nm}$. For reflectometric interference spectroscopy (RIfS), the PU solution was spin-coated onto glass substrates with a thin layer of tantalpentoxide ( $1 \mathrm{~mm}$ glass, $10 \mathrm{~nm} \mathrm{Ta}_{2} \mathrm{O}_{5}$ ). Here, the spincoated layer of PU served as the interference layer for the RIfS measurements. The concentration of the PU solution was adapted to result in a 310-380 nm optical thickness of the layer after the plasma treatment.

Plasma surface modifications of the polymer films were performed in a FEMTO low pressure plasma system (Diener electronic, Ebhausen, Germany) consisting of a borosilicate glass round vacuum and a low-frequency $(40 \mathrm{kHz})$ generator using oxygen plasma. A previous study investigated the plasma modification of PU according to a statistical experimental design. ${ }^{25}$ Based on this study, to achieve varied modifications with few plasma parameters, the process time and pressure were varied between 0.2-3.0 minutes and 0.2-0.8 mbar (Table 1). The applicable power was kept constant at $100 \mathrm{~W}$.

2.1.2 DY-490 labeling of fibronectin. For covalent, fluorescence labeling of human FN (F1056-2MG, Sigma-Aldrich, St. Louis, USA), Dyomics DY-490 N-Hydroxysuccinimid-Ester (FluoroSpin 490 Protein Labeling \& Purification Kit, emp biotech, Berlin, Germany) was used according to the manufacturer's instructions with a 20 -fold molar excess of reactive dye to protein molecules. The resulting concentration and the degree of labeling (2.6 dye molecules per FN) was determined optically, measuring the absorbance at $280 \mathrm{~nm}$ and $493 \mathrm{~nm}$ with a NanoDrop 2000 spectrophotometer (Thermo Fisher Scientific, Waltham, USA).

2.1.3 Fibronectin adsorption. After oxygen plasma treatment, samples were disinfected with $70 \%$ ethanol for $10 \mathrm{~min}$ and rinsed in phosphate buffered saline (PBS). The samples were then incubated for 1 hour at $37{ }^{\circ} \mathrm{C}$ with $10 \mu \mathrm{g} \mathrm{ml}{ }^{-1}$ human FN $\left(10 \mu \mathrm{g} \mathrm{ml}^{-1}, \mathrm{~F} 1056-2 \mathrm{MG}\right.$, Sigma-Aldrich, St. Louis, USA) that was dissolved in PBS.

\subsection{Characterization of the surfaces}

2.2.1 X-ray photoelectron spectroscopy. Photoelectron spectroscopy (XPS) was carried out using a multi-chamber ultrahigh vacuum system (base pressure $8 \times 10^{-10} \mathrm{mbar}$ ) equipped with a Phoibos 100 analyzer and a $1 \mathrm{~d}$ - Delay Line detector (SPECS, Berlin, Germany). Al-K $\alpha$ radiation of a conventional $\mathrm{Al} / \mathrm{Mg}$ anode (XR-50 m X-ray source, $h \nu=1486.6 \mathrm{eV}$ ) 
was used for the measurements. The core-level spectra of the $\mathrm{C}$ 1s peaks were collected with $20 \mathrm{eV}$ pass energy. The program Unifit version 2018 (Unifit scientific software, Leipzig, Germany) was used for spectral analysis identifying the plasma-induced groups (Fig. S1 and Table S1, ESI $\dagger$ ). ${ }^{29}$

2.2.2 Contact angle measurements. Changes in wettability were determined through static contact angle measurements at room temperature using the sessile drop method on the CAM 200 optical angle goniometer (KSV Instruments LTD, Helsinki, Finland). The time between the flooding of the plasma chamber and the placement of the first test liquid drop of $\mathrm{H}_{2} \mathrm{O}$ was 2.5 minutes. 5 drops were placed on different areas on each sample. The drop volume was $2 \mu \mathrm{l}$. The protein-coated samples were rinsed with distilled water and dried under a cold nitrogen stream before measurements were taken.

2.2.3 Atomic force microscopy. The surface topography of the samples was investigated with atomic force microscopy (AFM) using a Nanoscope III multi-mode AFM system operating in ScanAsyst PeakForce and TappingMode (Bruker, Billerica, MA, USA). ScanAsyst-Air-HR probes (Bruker) were selected with a spring constant of $0.4 \mathrm{~N} \mathrm{~m}^{-1}$ and a resonance frequency of $130 \mathrm{kHz}$ for the PeakForce measurements, while the RTESPA150 probes (Bruker) with a $150 \mathrm{kHz}$ frequency were used for tapping mode. The open source program Gwyddion version 2.49 was used for AFM image analysis and qualitative rootmean-squared roughness $r(\mathrm{RMS})$ estimations on a $1 \mu \mathrm{m}^{2}$ area. $^{30}$

2.2.4 Reflectometric interference spectroscopy. RIfS, a label-free optical method, was used to investigate the adsorption of FN onto the modified PU surfaces in a time-resolved manner. ${ }^{31}$ The PU films were incubated in PBS for $40 \mathrm{~min}$ before the FN adsorption measurements were started. This process was monitored by RIfS. In case of no further drift, different concentrations of FN in PBS $\left(1 \mu \mathrm{g} \mathrm{ml} l^{-1}, 3.3 \mu \mathrm{g} \mathrm{ml}^{-1}\right.$, $6.6 \mu \mathrm{g} \mathrm{ml}^{-1}, 10 \mu \mathrm{g} \mathrm{ml}^{-1}, 13.3 \mu \mathrm{g} \mathrm{ml}^{-1}, 16.6 \mu \mathrm{g} \mathrm{ml}^{-1}$ and $20 \mu \mathrm{g} \mathrm{ml}^{-1}$ ) were pumped across the PU surface (pumping speed: $0.5 \mu \mathrm{s} \mathrm{s}^{-1}$, flow cell diameters: width: $1 \mathrm{~mm}$, height: $0.1 \mathrm{~mm}$ ) for 33 minutes (Fig. S2, ESI $\dagger$ ). The change in optical thickness $(\Delta n \cdot d)$ was calculated from the recorded interference spectrum as described by Kraus et al. ${ }^{31}$ The kinetic parameters, the association rate constant $k_{\mathrm{a}}$, and the dissociation rate constant $k_{\mathrm{d}}$ of the FN adsorption onto the PU surface were evaluated from the binding curves of FN at different concentrations according to O'Shannessy et al. ${ }^{32}$ The application of this basic model results in the mean $k_{\mathrm{a}}$ and $k_{\mathrm{d}}$ of the adsorption process over the investigated time and different binding sites of the protein.

2.2.5 Laser scanning confocal fluorescence microscopy of fluorescence-labeled fibronectin. Adsorption of the fluorescence-labeled FN on glass slides with plasma-treated PU was determined with a custom-built confocal microscope. An oil immersion objective lens (NA $=1.46)$ was used to focus laser light of $488 \mathrm{~nm}$ (LDH-D-C-485, PicoQuant, Berlin, Germany) with a repetition frequency of $20 \mathrm{MHz}$ and a power of $15 \mathrm{nW}$ to a diffraction limited spot. The fluorescence was detected with the same objective and guided through a pinhole and a long-pass filter (F76-490, AHF, Tübingen, Germany) to an avalanche photodiode (SPCM-AQR-13, PerkinElmer, Waltham,
USA). The fluorescence signal was collected by scanning the sample with a piezo-electric scanning stage over a square area of $100 \mu \mathrm{m}^{2}$ at several positions on three different samples (Fig. S3, ESI $\dagger$ ).

2.2.6 Anti-fibronectin immunofluorescence staining. After FN adsorption, the surfaces were washed once with PBS and blocked with $2 \%(\mathrm{w} / \mathrm{w})$ goat block solution for 30 minutes. Subsequently, the surfaces were incubated over night at $4{ }^{\circ} \mathrm{C}$ with a polyclonal anti-FN antibody $(1: 500$, F3648-100UL, Sigma-Aldrich, St. Louis, USA) and a monoclonal anti-FN antibody, which is described to bind against the flexible linker between the 9th and 10th type III repeat of $\mathrm{FN}^{33}$ (HFN7.1, 1:200, ABIN284417, antibodies-online, Aachen, Germany). After washing once with PBS, the samples were incubated with goat anti-rabbit IgG-Alexa Fluor $^{\circledR} 546$ and goat anti-mouse IgG-Alexa Fluor $\Delta 488$ (both 1:250, Thermo Fisher Scientific) for 45 minutes in the dark. ${ }^{34}$ Images were acquired by using a Zeiss fluorescence microscope (Cell Observer, Carl Zeiss AG, Oberkochen, Germany). The focal plane was adjusted manually for each image.

\subsection{Cell culture}

For cell-material studies, human primary-isolated microvascular endothelial cells (HMVECs) were isolated from the foreskin biopsies under the ethics approval no. 495/2018BO2 (IRB, University Hospital Tübingen) by enzymatic digestion with dispase and trypsin as previously described. ${ }^{35}$ Cells were cultured in endothelial cell growth medium MV (C-22020, PromoCell, Heidelberg, Germany) and used between passages 2 and 4. Human umbilical vein endothelial cells (HUVECs, C-12205, PromoCell, Heidelberg, Germany) were cultured in endothelial cell growth medium (C-22010, PromoCell) and used between passages 4 and $6 .{ }^{36}$ For cell-material-interaction experiments, 400 cells $\mathrm{mm}^{-2}$ were seeded on the FN-adsorbed surfaces and incubated for 24 hours at $37{ }^{\circ} \mathrm{C}$ and $5 \% \mathrm{CO}_{2}$.

\subsection{Immunocytochemistry}

After cell culture experiments, the cell-seeded PU samples were washed with $\mathrm{PBS}^{-}$and fixed with $4 \%(\mathrm{w} / \mathrm{w})$ paraformaldehyde in PBS for 10 minutes. In order to reduce nonspecific binding, the cells were incubated with $2 \%(\mathrm{w} / \mathrm{w})$ goat block solution for 30 minutes. Cells were incubated with anti-FN $(1: 200$, ab2413, Abcam, Cambridge, UK), anti-CD31 (PECAM-1; 1 : 100, sc-71872, Santa Cruz, USA), anti-von Willebrand factor $(1: 200$, A0082, DAKO, Glostrup, Denmark), anti-focal adhesion kinase (FAK; 1:100, PA5-17591, Thermo Fisher scientific, Waltham, USA), anti-VE-Cadherin $(1: 250$, HPA004726, Sigma-Aldrich, St. Louis, USA) and anti-vinculin (1:500, MAP3574, Milipore, Burlington, USA) over night at $4{ }^{\circ} \mathrm{C}$. One primary antibody of the same species was used per sample. After washing with PBS, samples were incubated with goat anti-mouse IgG-Alexa Fluor ${ }^{\circledR} 488$, goat anti-rabbit IgG-Alexa Fluor ${ }^{\mathbb{B}} 546$ (both $1: 250$, Thermo Fisher Scientific) and Alexa Fluor ${ }^{\circledR} 647$ Phalloidin (1:1000, A22283, Thermo Fisher Scientific) for 45 minutes in the dark. Finally, nuclei were counterstained with DAPI (10236276001, Roche, Basel, Switzerland). Images were observed by using a 
Zeiss fluorescence microscope (Cell Observer, Carl Zeiss AG, Oberkochen, Germany).

\subsection{Image analysis}

Polyclonal and monoclonal anti-FN IF staining was quantified by measuring the relative pixel intensity (RPI) of the immunofluorescence images. Counting the DAPI-stained cell nuclei per area determined the number of adherent cells. The formation of focal adhesions was quantified by counting the vinculin and FAK foci per cell. To assess VE-cadherin and PECAM-1 expression as well as F-actin organization, the area within a defined fluorescence intensity threshold was measured and normalized to the cell number. All images were analyzed using ImageJ. ${ }^{37}$

\subsection{Statistical analysis}

Results are presented as mean \pm standard deviation. For statistical analysis, a one-way ANOVA/Fisher's Least Significant Difference test was performed using Origin 2018 (OriginLab, Northampton, MA, USA). Probability values of 95\%, 99\% and 99.9\% were used to determine significance.

\section{Results}

\subsection{Analysis of the surface chemistry and its influence on FN adsorption}

XPS, AFM and contact angle measurements showed that surface roughness affects the hydrophilic character of the polymers and FN adsorption behavior (Fig. 1). According to the XPS data (Fig. 1a, Fig. S1, ESI $\dagger$ ), the chemical composition of the sample surfaces was separable into plasma-incorporated functional groups and PU-specific functionalities. The plasmagenerated $-\mathrm{OH}$ functional groups and the polymers $\mathrm{C}-\mathrm{O}-\mathrm{C}$ species peaks are situated on identical binding energies, and therefore could not be adequately separated within the functional group content calculations. From the XPS data analysis it was discernible that samples A and B had a higher $-\mathrm{COOH}$ and $\mathrm{C}=\mathrm{O}$ content than all other samples, while the $\mathrm{C}, \mathrm{D}$ and $\mathrm{E}$ surfaces had a high content of $-\mathrm{OH}$ and $\mathrm{C}-\mathrm{O}-\mathrm{C}$ functionalities (Fig. 1a). The untreated control surface $\mathrm{F}$ had no new plasmacreated species. In terms of surface roughness, the untreated sample F showed a smooth surface that was only little impacted by most plasma treatments (Fig. 1b). Only surface A, treated for a longer time under low oxygen pressure, exhibited a clearly higher surface roughness compared to the other samples. (Fig. 1b). This effect was also seen in the water contact angle measurements of the series (Fig. 1c). The untreated F surface had the highest contact angle with $71.1^{\circ} \pm 1.6^{\circ}$. In contrast, the surfaces C, D and E, which were similar in chemical composition and roughness, were only slightly more hydrophilic with similar contact angle values ranging around $50^{\circ}\left(\mathrm{C}: 48.2^{\circ} \pm 0.6^{\circ}\right.$ versus $\mathrm{D}: 50.8^{\circ} \pm 1.7^{\circ}, p<0.05$; C versus $\mathrm{E}: 54.3^{\circ} \pm 1.0^{\circ}, p<$ 0.001 ; D versus $\mathrm{E}, p<0.05$ ). Since the roughness was less impacted by these plasma treatments, the biggest contribution to the hydrophilization of these surfaces came from the introduced hydroxyl groups. While the $-\mathrm{COOH}$ and $\mathrm{C}=\mathrm{O}$ surface coverage of the samples A and B was very similar, the contact angle of surface $\mathrm{A}\left(17.5^{\circ} \pm 1.9^{\circ}\right)$ was half as high compared with surface $\mathrm{B}\left(33.4^{\circ} \pm 2.7^{\circ}\right)$. The major contribution to this additional lowering of the contact angle of the longer plasmatreated sample came from the increased surface roughness,
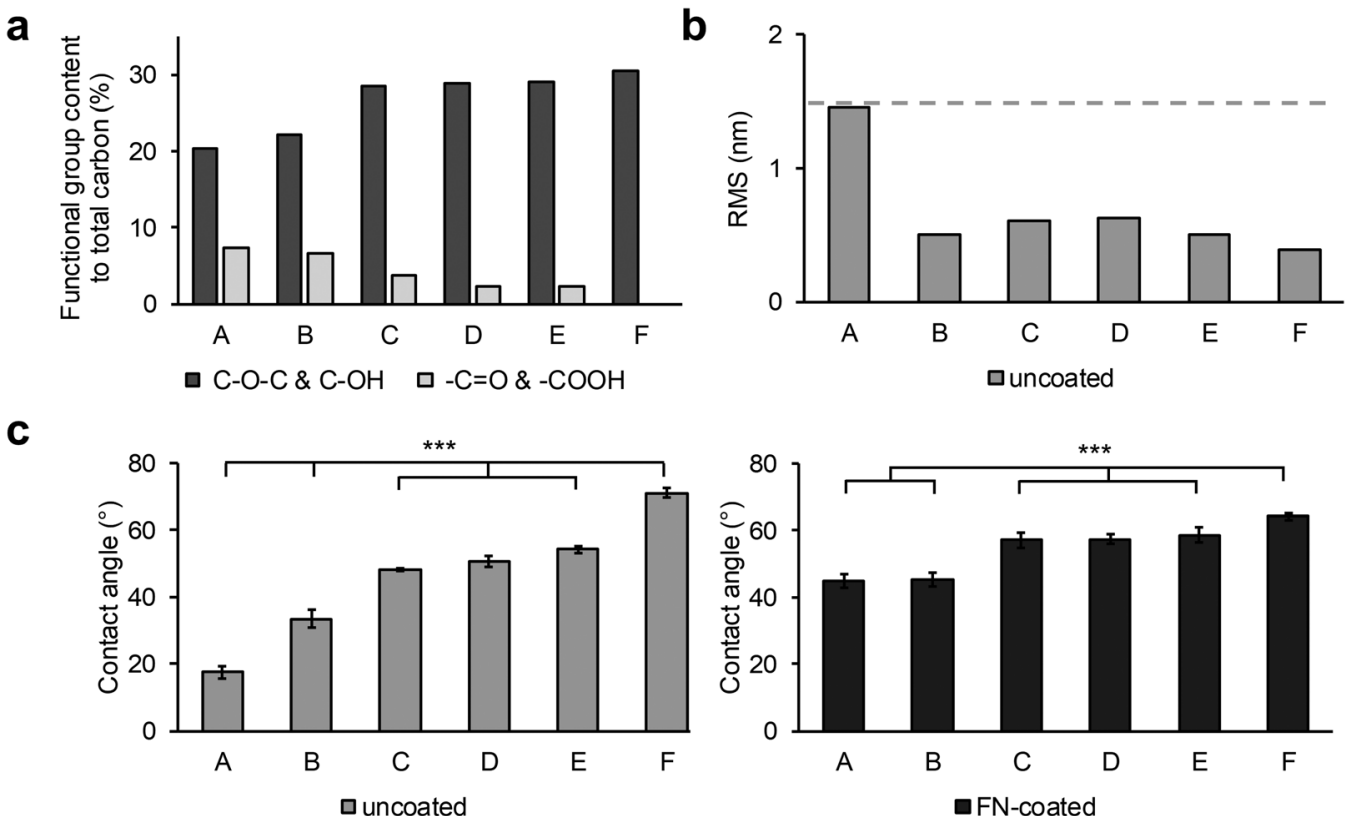

Fig. 1 Investigation of plasma modifications on the PU surfaces and adsorption of fibronectin. (a) XPS obtained chemical composition of plasmainduced functional groups on the polymer surface before FN coating. (b) Qualitative roughness analysis $r$ (RMS) of the polymer surfaces after plasma treatment. The dash line represents the maximum roughness value. (c) Contact angle analysis of plasma-treated and untreated surfaces before (left, "uncoated", one-way ANOVA, $n=3, p^{\star \star *}<0.001$ ) and after FN coating (right, "FN-coated", one-way ANOVA, $n=3, p^{\star \star *}<0.001$ ). (d) AFM topography images of sample surfaces after FN coating. Scale bar equals $200 \mathrm{~nm}$. 
which was twice as high as every other sample (A: $1.45 \mathrm{~nm}$ versus $\mathrm{B}: 0.5 \mathrm{~nm}, \mathrm{C}: 0.61 \mathrm{~nm}, \mathrm{D}: 0.63 \mathrm{~nm}, \mathrm{E}: 0.5 \mathrm{~nm}$ and F: $0.39 \mathrm{~nm})$.

The water contact angles and $r$ (RMS) were also measured after FN coating of the samples (Fig. 1c, "FN-coated", Fig. 2a). As with the previous contact angle series, surface $\mathrm{F}\left(64.2^{\circ} \pm 1.1^{\circ}\right)$ was the least hydrophilic with the lowest change in the contact angle after FN coating (Table S2, ESI $\dagger$ ). Samples C, D, and E had a contact angle of around $57^{\circ}$ (C: $57.2^{\circ} \pm 2.3^{\circ}$, D: $57.4^{\circ} \pm 1.5^{\circ}$, E: $58.7^{\circ} \pm 2.1^{\circ}$, not significant). Unlike surface $\mathrm{F}$, the $\mathrm{A}\left(45.0^{\circ} \pm 2.0^{\circ}\right)$ and $\mathrm{B}\left(45.3^{\circ} \pm 2.0^{\circ}\right)$ surfaces showed an increase in contact angle with the same result at about $45^{\circ}$. The AFM images, recorded after FN coating, resulted in visible topographic changes and increase in roughness compared with their uncoated counterparts only for the control sample F (Fig. 1d). From the height contrast images, and extracted height profiles of the images, no difference between the plasma treated FN-coated surfaces was visible (Fig. 2). The protein domains and the polymer background were indistinguishable, as was the case with phase AFM imaging (Fig. S4 and S5, ESI $\dagger$ ). Through the plasma treatment of the samples, the FN proteins lost their material contrast with the polymer. The untreated surface (sample F) had a noticeable increased roughness after the protein coating, from approximately
0.4 to $3.1 \mathrm{~nm}$, which was due to topographical changes caused by the protein network rather than modifications in the PU layer. This network was partially up to $10 \mathrm{~nm}$ high with differently sized pores ranging from $200 \mathrm{~nm}$ to $500 \mathrm{~nm}$ in diameter.

In order to study protein adsorption kinetics, the adsorption of FN on the oxygen plasma-treated PU surfaces was monitored by RIfS. An exemplary binding curve is depicted in Fig. 3a showing the baseline (with PBS), followed by the association of FN (with the FN solution), starting at the time point $0 \mathrm{~s}$, and the dissociation (rinsing with PBS) of FN from $2000 \mathrm{~s}$ to $4000 \mathrm{~s}$. The recorded binding curves (Fig. S2, ESI $\dagger$ ) showed a different adsorption behavior of $\mathrm{FN}$ on the surfaces. These differences were evaluated by calculating the respective association rate constant $k_{\mathrm{a}}$ and dissociation rate constant $k_{\mathrm{d}}$ using a basic kinetic model (Fig. $3 \mathrm{~b}$ and c). FN showed on all surfaces small $k_{\mathrm{d}}$ values in the magnitude of $10^{-3} \mathrm{~s}^{-1}$. On surface $\mathrm{F}, \mathrm{FN}$ exhibited the highest $k_{\mathrm{d}}$ value compared to all other investigated surfaces, indicating an easier desorption of FN from surface $\mathrm{F}$. The calculated $k_{\mathrm{a}}$ values showed faster rates of the forward adsorption process on surface $\mathrm{A}, \mathrm{E}$ and $\mathrm{F}$ in comparison to the surfaces $\mathrm{B}, \mathrm{C}$ and $\mathrm{D}$. The larger error of the fit of the calculated rate constants on the surfaces $\mathrm{A}, \mathrm{E}$ and $\mathrm{F}$ in respect to the surfaces B, C and D demonstrated a larger discrepancy

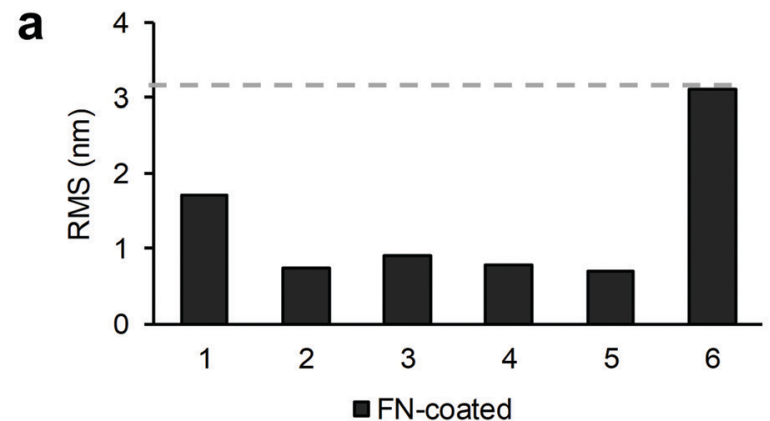

b
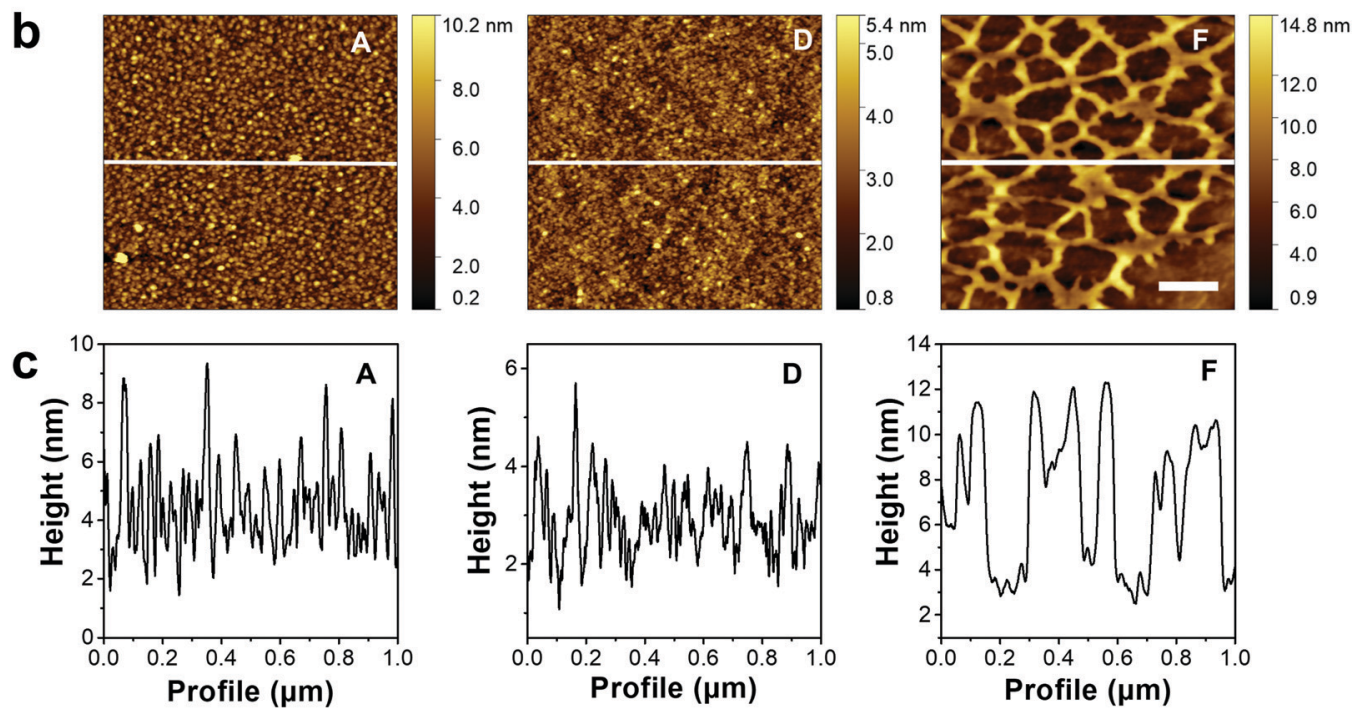

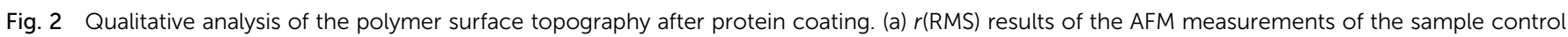

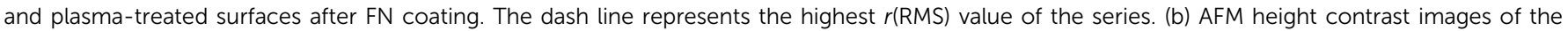

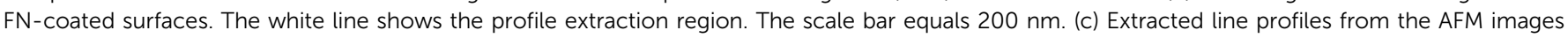
showing the structure of the surface. 
a

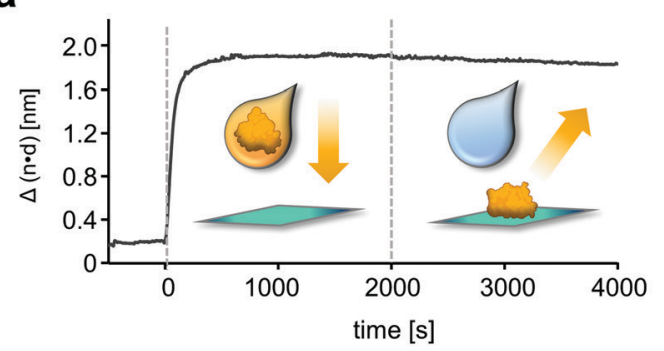

C

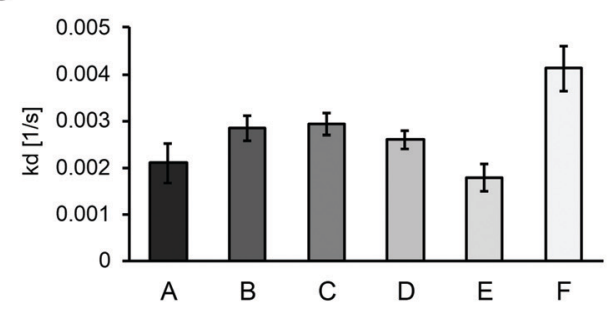

e

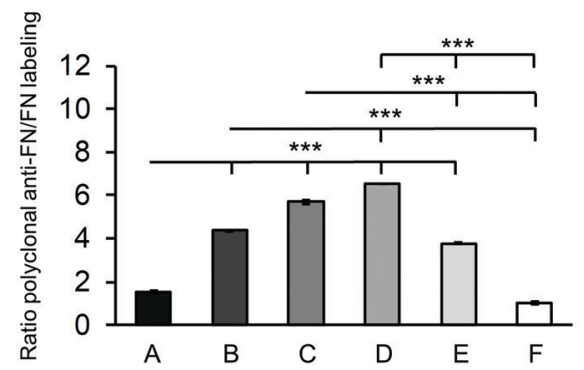

b

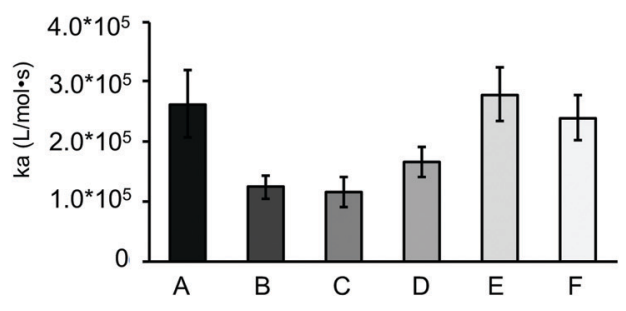

d

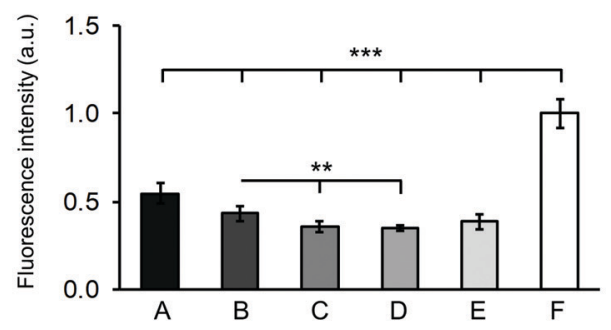

f

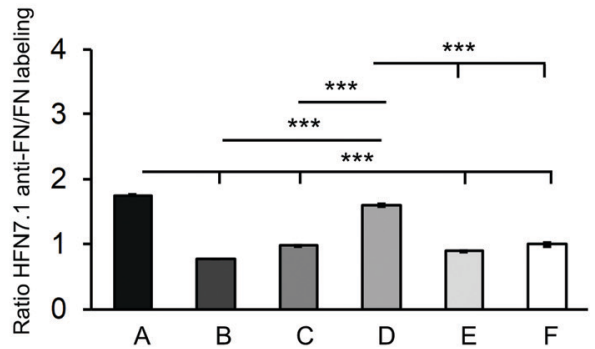

Fig. 3 The adsorbed fibronectin varies in adsorption kinetics, amount and conformation on different hydrophilic surfaces. (a) Exemplary binding curve of $10 \mu \mathrm{g} \mathrm{ml}^{-1} \mathrm{FN}$ on surface F. Association (with the FN solution) of FN starting at time point $0 \mathrm{~s}$ and dissociation (with PBS) of FN from $2000 \mathrm{~s}$ to $4000 \mathrm{~s}$. Calculated association rate constants $\left(k_{\mathrm{a}}\right)(\mathrm{b})$ and calculated dissociation rate constants $\left(k_{\mathrm{d}}\right)$ (c) of FN adsorption. Error bars depict the error of the fit. (d) Fluorescence intensity of labeled FN that was coated on the different surfaces. Data is shown relative to surface F. (e) Ratio of the polyclonal anti-FN immunofluorescence staining and the labeled FN. (f) Ratio of the monoclonal anti-FN immunofluorescence staining targeting the cell binding domain and the labeled FN. One-way ANOVA, $n=3,{ }^{* *} p<0.01,{ }^{* \star *} p<0.001 ;$ RPI = relative pixel intensity.

from the assumed first order kinetic model on the surfaces A, $\mathrm{E}$ and F.

The relative amount of the total adsorbed FN on the different plasma-treated samples was determined indirectly by comparing the fluorescence intensity of DY-490 labeled FN after laser excitation (Fig. 3d). As the degree of labeling is consistent throughout the FN molecules, the amount of fluorescence intensity is directly linked to the amount of FN molecules on the surface. While sample $\mathrm{F}$ showed the highest fluorescence signal and therefore the highest amount of FN $(1.00 \pm 0.08)$, sample A revealed about half of it $(0.54 \pm 0.06)$. Samples C, D and $\mathrm{E}$ showed the same fluorescence intensity, which was significantly lower than sample A (A versus C: $0.36 \pm 0.03$, $p<0.001$; A versus $\mathrm{D}: 0.35 \pm 0.02, p<0.001$; A versus $\mathrm{E}$ : $0.39 \pm 0.04, p<0.001$ ), sample B (B: $0.43 \pm 0.04$ versus $\mathrm{C}$, $p<0.01$; $\mathrm{B}$ versus $\mathrm{D}, p<0.01$ ), and sample $\mathrm{F}$ (F versus $\mathrm{B}$, $p<0.001$; F versus C, $p<0.001$; F versus $\mathrm{D}, p<0.001$ ), which indicated fewer FN amounts on these surfaces.

The orientation and conformation of the adsorbed FN was further investigated with IF staining using a polyclonal antibody against the full-length FN (Fig. 3e and Fig. S6a, ESI $\dagger$ ).
The ratio of the anti-FN staining to the amount of adsorbed FN, determined by the fluorescence-labeled FN, indicates conformational and orientation changes of the protein. Comparing the polyclonal anti-FN/FN labeling ratios of the different surfaces, a similar result was found on the surfaces $C$ and $D$. Compared to them, the ratios on the A, B, E and F surfaces were significantly lower (A: $1.54 \pm 0.05$ versus $\mathrm{C}$ : $5.68 \pm 0.07$, A versus D: $6.51 \pm 0.01$, B: $4.35 \pm 0.01$ versus $\mathrm{C}$, B versus $\mathrm{D}, \mathrm{E}: 3.77 \pm 0.05$ versus $\mathrm{C}, \mathrm{E}$ versus $\mathrm{D}, \mathrm{F}: 1.00 \pm 0.06$ versus $\mathrm{C}, \mathrm{F}$ versus $\mathrm{D}$, all $p<0.001$ ). The $\mathrm{FN}$ coating on the $\mathrm{A}$ and $\mathrm{F}$ surfaces even showed a significantly lower value compared with the B and $\mathrm{E}$ surfaces (all $p<0.001$ ). Additionally, the adsorbed FN was stained with a monoclonal antibody (Fig. S6b, ESI $\dagger$ ), whose epitope maps to a segment between the 9th and 10th type III repeat (HFN7.1), indicating the availability of the cell binding domain. ${ }^{38}$ The ratio of the monoclonal antibody to the amount of adsorbed FN showed significantly higher signals on the A and D surfaces compared with the surfaces B, C, E and F (A: $1.74 \pm 0.01$ versus $\mathrm{B}: 0.77 \pm 0.00$, A versus $\mathrm{C}: 0.98 \pm 0.01$, A versus $\mathrm{E}: 0.89 \pm 0.01$, A versus $\mathrm{F}: 1.00 \pm 0.03$, D: $1.60 \pm 0.02$ versus $\mathrm{B}, \mathrm{D}$ versus $\mathrm{C}, \mathrm{D}$ versus $\mathrm{E}, \mathrm{D}$ versus $\mathrm{F}$, all $p<0.001$ ), 
suggesting a more exposed cell binding domain of the FN on these surfaces (Fig. 3f).

\subsection{Investigation of the endothelial cell-material-interaction on the FN-coated surfaces}

The investigation of the endothelial cell-material-interaction on the different surfaces was of particular interest as it provides information to predict the behavior of the cells depending on surface properties and FN deposition. For this purpose, HUVECs and HMVECs were utilized.

First, the number of adherent HUVECs and HMVECs was investigated 24 hours after seeding showing a rather similar distribution of adherent cells on the different surfaces (Fig. 4a and b). However, on surfaces A and E, significantly less adherent HUVECs and HMVECs were found when compared with the surfaces B and D (HUVECs: A: $0.97 \pm 0.01$ versus B: $1.16 \pm 0.04$, $p<0.01$ and D: $1.15 \pm 0.05, p<0.05$; E: $0.95 \pm 0.10$ versus $\mathrm{B}$ and D, $p<0.01$; HMVECs: A: $0.87 \pm 0.04$ versus $\mathrm{B}: 1.04 \pm 0.05$ and D: $1.05 \pm 0.07, p<0.001$; E: $0.92 \pm 0.60$ versus $\mathrm{B}$, $p<0.001$ and $\mathrm{D}, p<0.01$, cell count was normalized to surface F). In addition, the HUVECs showed a significantly increased cell count on surface $\mathrm{C}$ compared to surface $\mathrm{A}$ and $\mathrm{E}$ (C: $1.11 \pm 0.13$ versus $\mathrm{A}$ and $\mathrm{E}, p<0.05$ ). For the HUVECs, but not for the HMVECs, significantly fewer adherent cells were found on surface $\mathrm{F}$ compared to surfaces $\mathrm{B}$ and $\mathrm{D}$ (F: $1.00 \pm 0.09$ versus $\mathrm{B}$ and $\mathrm{D}, p<0.05)$. Both cell types showed no significant differences in the number of adherent cells between the B, C and D surfaces, and between the A and $\mathrm{E}$ samples.

The different surfaces did not appear to influence the size of the two cell types, although the HUVECs tended to be smaller on the surfaces B and C compared to the other samples, and larger on surfaces C, D and E (Fig. S7, ESI $\dagger$ ).

The interaction of HUVECs and HMVECs with the preadsorbed FN layer led to a FN reorganization, which was demonstrated by anti-FN IF staining (Fig. 5a and Fig. S8, ESI $\dagger$ ). Both cell types showed fibrillar structures on the A surface in the area of the cells (Fig. 5a, white arrow). In addition, FN reorganization appeared on all surfaces as dark areas around the cells, most notably in the $\mathrm{C}$ and D samples (Fig. 5a, white dotted arrow).
The cytoskeleton was examined by using F-actin staining, as its distribution provides information about the barrier function of an endothelial cell. ${ }^{39}$ A distinct reorganization of the F-actin was observed on the different surfaces (Fig. 5 and Fig. S9, ESI $\dagger$ ). For both cell types, peripheral ventral stress fibers were found on the A and F surfaces with more prominent F-actin bundles on the A surface (Fig. 5b). In contrast, in the cells on the samples B, C, D and E, the stress fibers were distributed over the entire cell. A semi-quantitative analysis of the F-actinstained areas revealed a significantly lower amount of stress fibers in the cells cultured on the A surfaces compared with cells grown on surfaces B, D and E for both cell types (HUVECs: $\mathrm{A}: 0.71 \pm 0.06$ versus B: $1.39 \pm 0.31, \mathrm{D}: 1.35 \pm 0.19$ and $\mathrm{E}: 1.50 \pm$ $0.50, p<0.05$; HMVECs: A: $0.60 \pm 0.12$ versus $\mathrm{B}: 1.23 \pm 0.12$, $\mathrm{D}: 1.25 \pm 0.15$ and $\mathrm{E}: 1.36 \pm 0.13, p<0.05)$. In addition, the HMVECs showed a significantly lower signal on surface A compared with surface C (A versus C: $1.10 \pm 0.30, p<0.05$; Fig. 5c).

The integrin-mediated cell adhesion is associated with the formation of focal adhesions. ${ }^{40}$ Vinculin, a scaffolding protein that is involved in the mechanical regulation of focal adhesions, was studied by statistically analyzing the number of vinculin foci per cell (Fig. 6). ${ }^{41}$ Both cell types showed a significantly higher number of vinculin foci per cells on surface A compared with the other surfaces (HUVECs: A: $113 \pm 40$ versus B: $46 \pm 16, p<0.01$; A versus C: $57 \pm 41$, D: $51 \pm 10$, $\mathrm{E}: 56 \pm 7$ and F: $53 \pm 16, p<0.05$; HMVECs: A: $51 \pm 21$ versus B: $26 \pm 9$ and E: $27 \pm 11, p<0.05$; A versus C: $19 \pm 4$ and D: $21 \pm 5, p<0.01)$, with the exception of surface $\mathrm{F}(49 \pm 8)$ where a similar number of vinculin foci were counted in the HMVECs (Fig. 6a and b). For both cell types, the average number of foci per cell was similar for surfaces B, C, D and E.

Furthermore, the FAK, which plays a critical role in integrinmediated signal transduction, was examined (Fig. 6). ${ }^{42}$ For the HUVECs, the number of FAK foci per cell tended to be higher on the very hydrophilic surfaces (A: $40 \pm 10$, B: $32 \pm 18$ and C: $54 \pm 35$ ) than on the less hydrophilic surfaces (D: $25 \pm 10$, E: $27 \pm 5$ and F: $20 \pm 7$ ). Due to a high variation within the experiments, statistically significant more FAK foci per cells were only found on the $\mathrm{C}$ surface compared with the surface F (C: $54 \pm 35$ versus F: $20 \pm 7, p<0.05$ ) (Fig. $6 c$ and d). The HMVECs showed a slightly different behavior. They inclined to
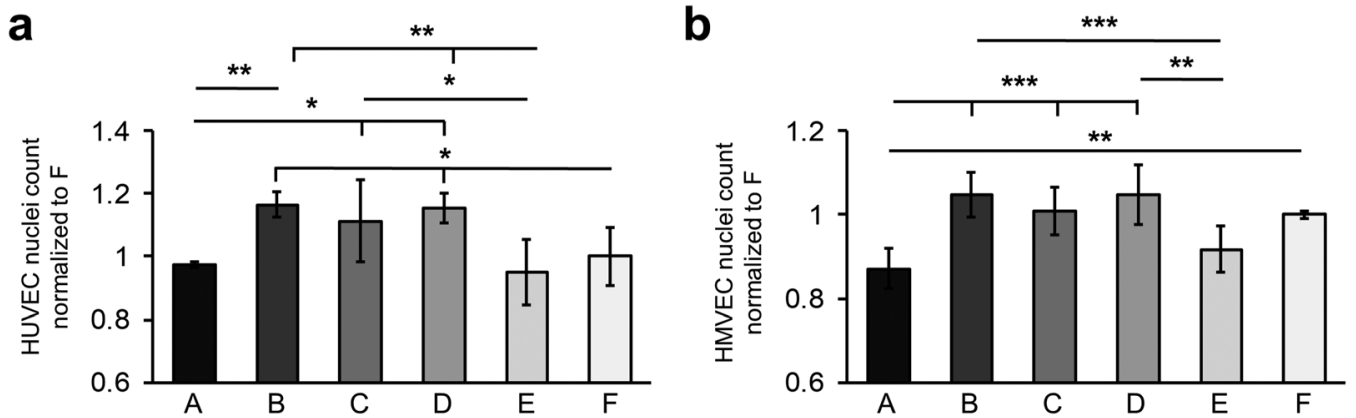

Fig. 4 Fibronectin coating on different hydrophilic surfaces impacts the number of adherent cells. The number of adherent (a) HUVECs and (b) HMVECs $24 \mathrm{~h}$ after cell seeding. Data is shown as change relative to F. One-way ANOVA, $n=3,{ }^{*} p<0.05,{ }^{* *} p<0.01,{ }^{* *} p<0.001$. 


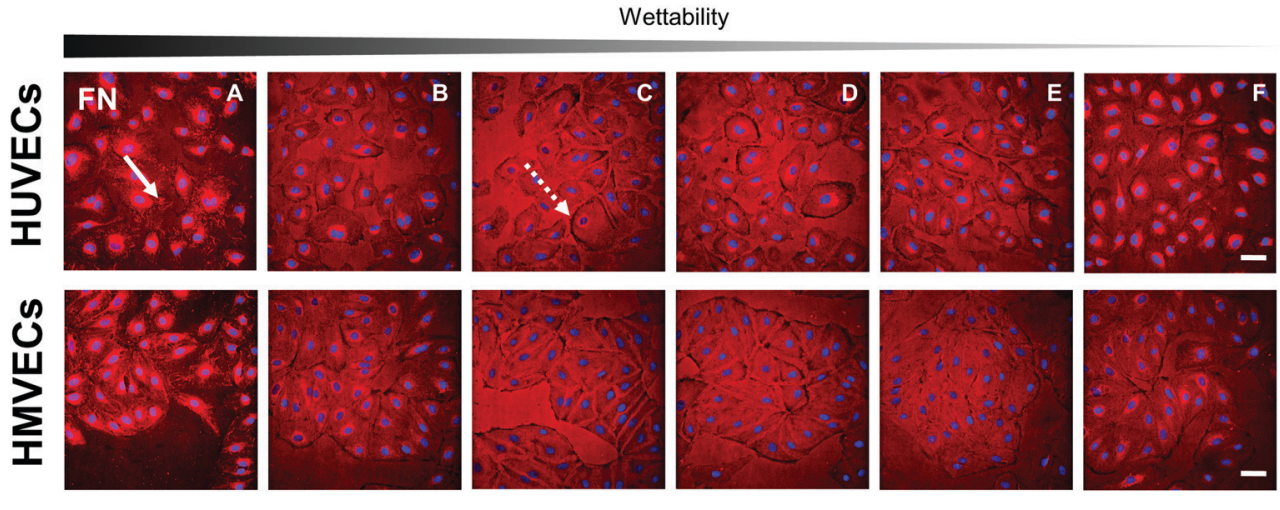

b
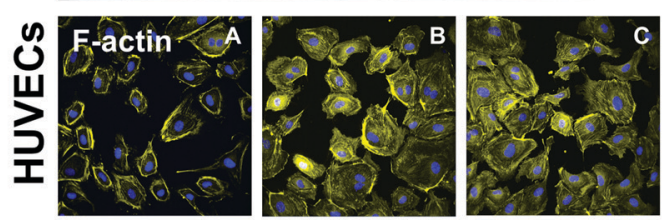

Wettability
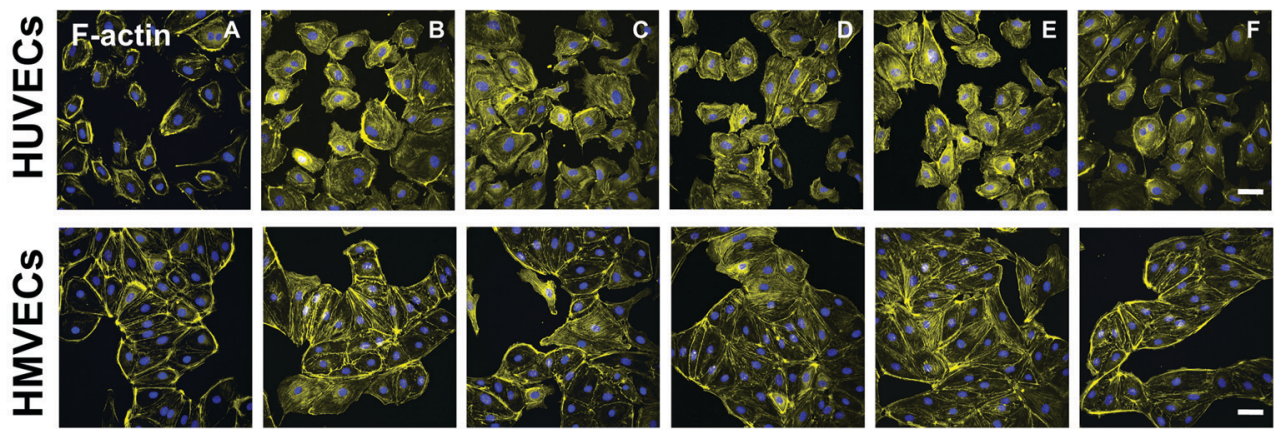

C
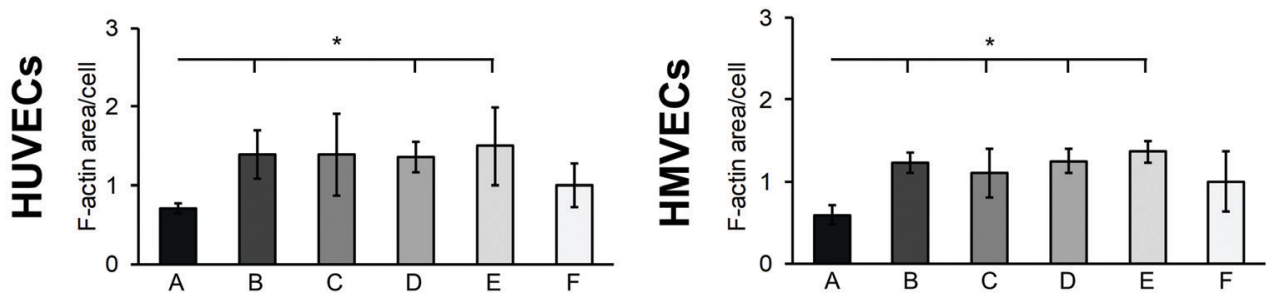

Fig. 5 Cell-fibronectin-interaction and F-actin reorganization in HUVECs and HMVECs. (a) Anti-FN immunofluorescence staining shows the interaction of HUVECs and HMVECs with the adsorbed FN, which is indicated by fibrillar structures (white arrow) and dark areas (white dotted arrow). Scale bars equal $100 \mu \mathrm{m}$. (b) Peripheral F-actin bundles are formed in HUVECs and HMVECs that are seeded on A and F surfaces. Scale bars equal $100 \mu \mathrm{m}$. (c) Semiquantitative area analysis of F-actin distribution in HUVECs and HMVECs. Data is shown relative to F. One-way ANOVA, $n=3,{ }^{*} p<0.05$.

form less FAK foci on the very hydrophilic surfaces compared with moderately hydrophilic surfaces. In detail, on surface B, significantly fewer FAK foci per cell were found compared to surfaces C and D (B: $12 \pm 12$ versus C: $42 \pm 18$ and D: $47 \pm 24$, $p<0.05$ ). Both cell types tended to form few FAK foci on the F surface; however, in the case of HMVECs the number of FAK foci per cell was significantly lower compared to surface D (D: $47 \pm 24$ versus $\mathrm{F}: 17 \pm 4, p<0.05$ ).

Cell-cell interactions were investigated by studying the expression of the endothelial cell type-specific markers VEcadherin and PECAM-1 (Fig. 7). Both proteins are located on the surface of endothelial cells and account for a large portion of the endothelial cell-to-cell junctions that contribute to the maintenance of the endothelial permeability barrier. ${ }^{43}$ Expression levels were evaluated by the IF-stained area per cell (Fig. 7b and d). The VE-cadherin staining showed similar expression levels for the HUVECs on all surfaces. Significant differences were found for the HMVECs (Fig. 7b and Fig. S10, ESI $†$ ). In detail, a higher VE-cadherin signal was detected on the A surface compared with surfaces B and F (A: $1.59 \pm 0.24$ versus B: $1.02 \pm 0.38$ and F: $1.00 \pm 0.39, p<0.05$ ). In addition, the cells on the $\mathrm{C}$ surface revealed a higher expression level compared with the B, D, E and F surfaces (C: $1.78 \pm 0.52$ versus $\mathrm{D}: 1.21 \pm 0.28$ and $\mathrm{E}: 1.30 \pm 0.34, p<0.05$ and versus $\mathrm{B}$ and $\mathrm{F}, p<0.01)$.

The PECAM-1 expression was the same for the HMVECs on all samples (Fig. 7c and d). For the HUVECs, less PECAM-1 was expressed in the cells on surface B compared with surface A. Interestingly, the HUVECs on surface B showed also a significantly lower expression of the endothelial cell marker von Willebrand factor (vWF) when compared with cells grown on surfaces D and F (B: $0.43 \pm 0.12$ versus $\mathrm{D}: 0.89 \pm 0.26$ and versus F: $1.00 \pm 0.57, p<0.05$; Fig. 8).

\section{Discussion}

In the present study, oxygen plasma surface treatment was used to incorporate hydroxyl, carbonyl, carboxyl and other oxygen-rich 
a

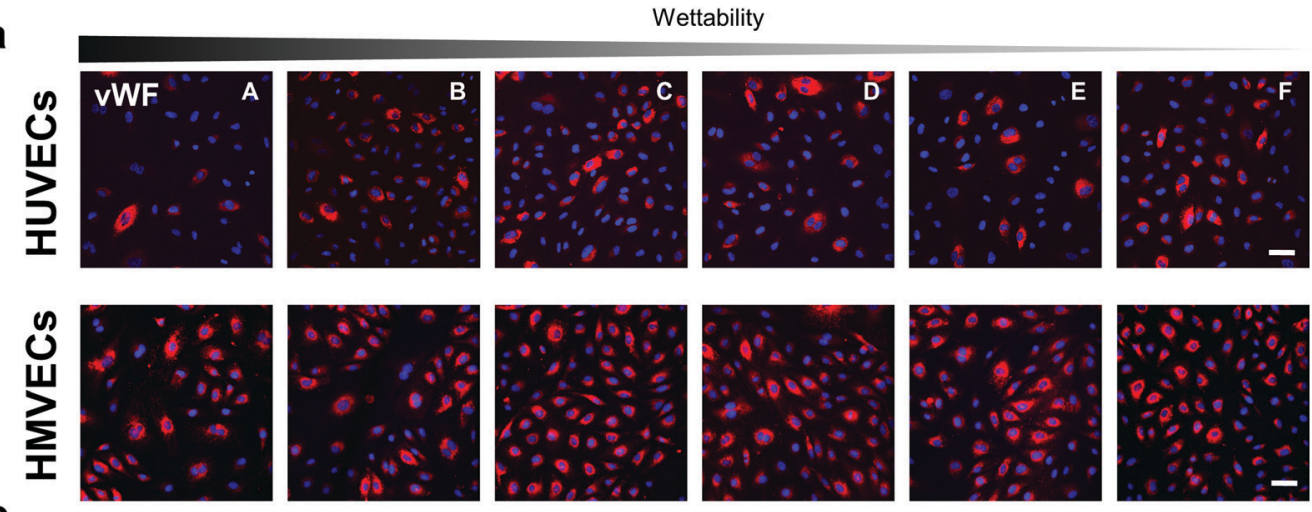

b
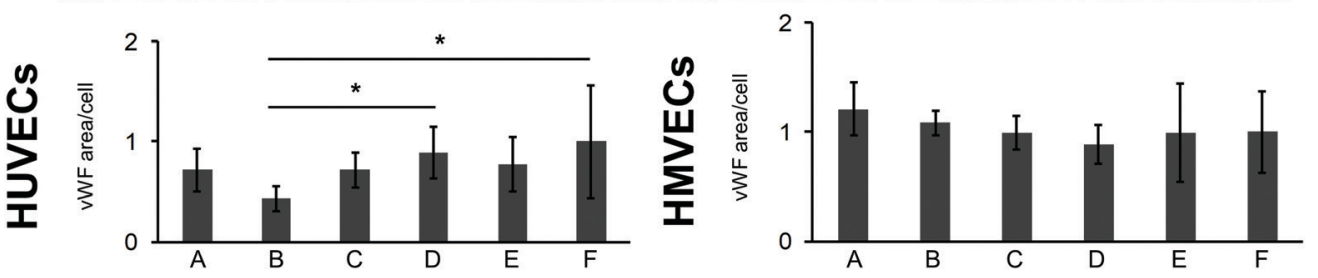

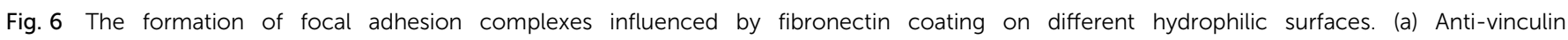

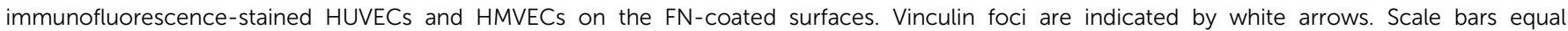

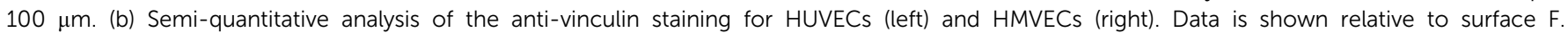

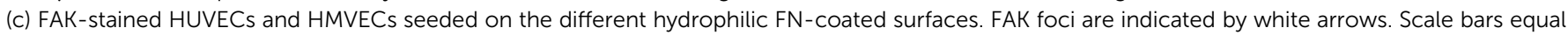

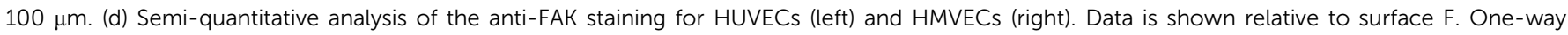
ANOVA, $n=3,{ }^{*} p<0.05,{ }^{* *} p<0.01$

groups onto PU surfaces in order to modify the polarity and chemical structure of the surface. ${ }^{44-49}$ During the plasma treatment, removal of material from the surface layer through plasma etching processes with UV irradiation and ion bombardment resulted in topographical changes. ${ }^{27,44,47}$ The impact of the plasma modification on the different surfaces was evaluated using AFM imaging, XPS analysis and contact angle measurements. The XPS and contact angle results showed that higher oxidized functional groups were incorporated with low oxygen pressure treatments, which led to a greater impact on PU surface hydrophilicity. ${ }^{25}$ From the contact angle measurements, specifically the low standard deviations of the samples, it can be concluded that the plasma treatment of the polymer surfaces had a high reproducibility. AFM measurements showed that an increased surface roughness contributed to lowering the contact angle, demonstrating a more hydrophilic surface. ${ }^{50}$ Especially with surface A, which has a similar chemical composition to surface $B$, the higher wettability can be attributed to surface roughness effects. This roughening of the sample topography was caused by the ablative nature of the oxygen plasma, which had a larger effect during the longer plasma treatment of sample A under low oxygen pressure conditions. FN-coated plasma-treated samples were difficult to distinguish using AFM topographic imaging; however, contact angle analysis showed differences between the plasma-treated samples. Only on the FN-coated control surface F, AFM images showed a fibrillar network that may be attributed to material-driven fibrillogenesis where FN molecules unfold and bind to each other. ${ }^{1,19,51}$

RIfS was employed to investigate the conformation and orientation of FN on the samples. Here, the kinetic inspection of the binding curves revealed different rate constants for the chemical forward and reverse process, indicating different interaction sites on the reactants. Surface A and B had a similar chemical composition; however, there was a pronounced difference in the calculated $k_{\mathrm{a}}$ on these surfaces, which could be attributed to the changed surface roughness and different reaction sites on the adsorbed FN. In contrast, the increase of $k_{\mathrm{a}}$ from surface $\mathrm{B}$ to $\mathrm{E}$ was induced by the changes in the chemical composition of the surfaces and the corresponding different reaction sites on FN. In our study, we identified the lowest $k_{\mathrm{a}}$ values for the surfaces $\mathrm{B}, \mathrm{C}$ and $\mathrm{D}$, and larger $k_{\mathrm{a}}$ values for the more hydrophilic surface $A$ as well as for the more hydrophobic surfaces E and F. This may be explained by the different influences of surface chemistry and surface roughness of the investigated PU surfaces on FN adsorption. A higher flexibility of FN on surface $\mathrm{F}$ in comparison to the other surfaces was found by a large $k_{\mathrm{a}}$ value and a coincidental large $k_{\mathrm{d}}$ value. Although FN appeared in a very stable fibrillary form on surface $\mathrm{F}$, it exhibited a more dynamic interaction towards the surface. The oversimplification of the actual processes at the surface by the applied kinetic model is reflected in the calculated error accompanying the results. ${ }^{52}$ The error was particularly large on surface A, E and F, indicating that the discrepancy from the Langmuir adsorption model was pronounced on these surfaces. On surface F, the lateral interactions between the adsorbed proteins in the network demonstrated by the AFM measurements (Fig. 1 and 2) can cause the discrepancy from the adsorption model. It is also very plausible that FN underwent greater conformational changes on surfaces A, E and F during adsorption when compared with surfaces B, C 
a

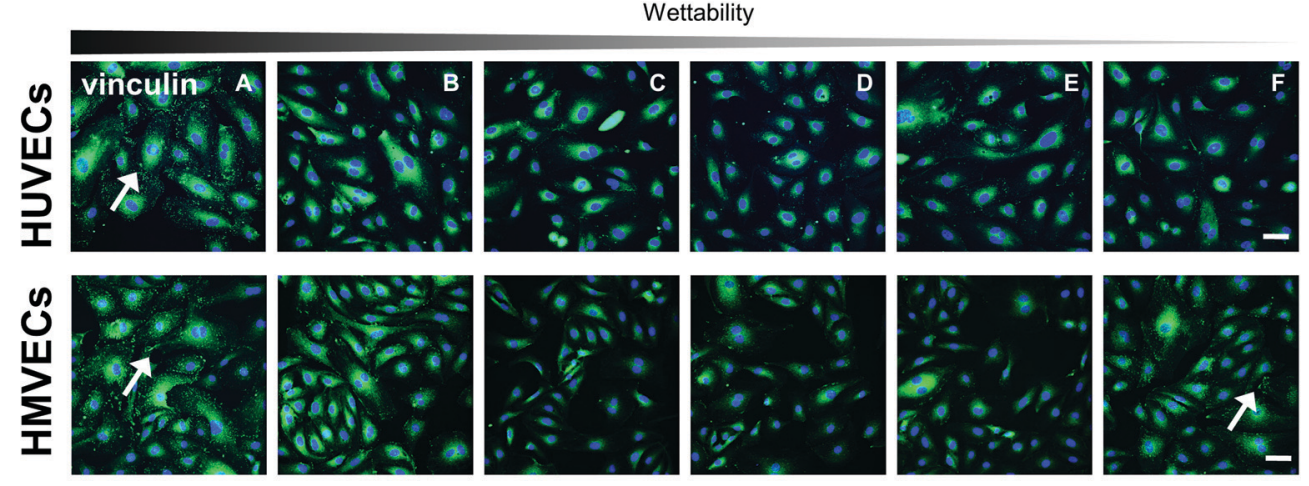

b
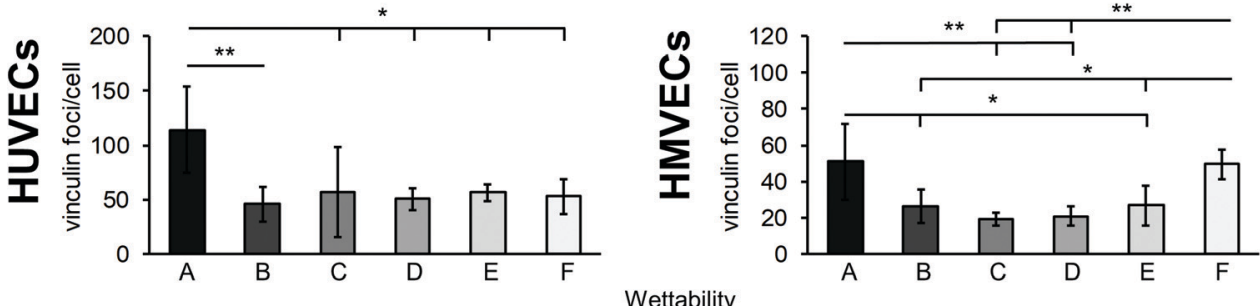

C
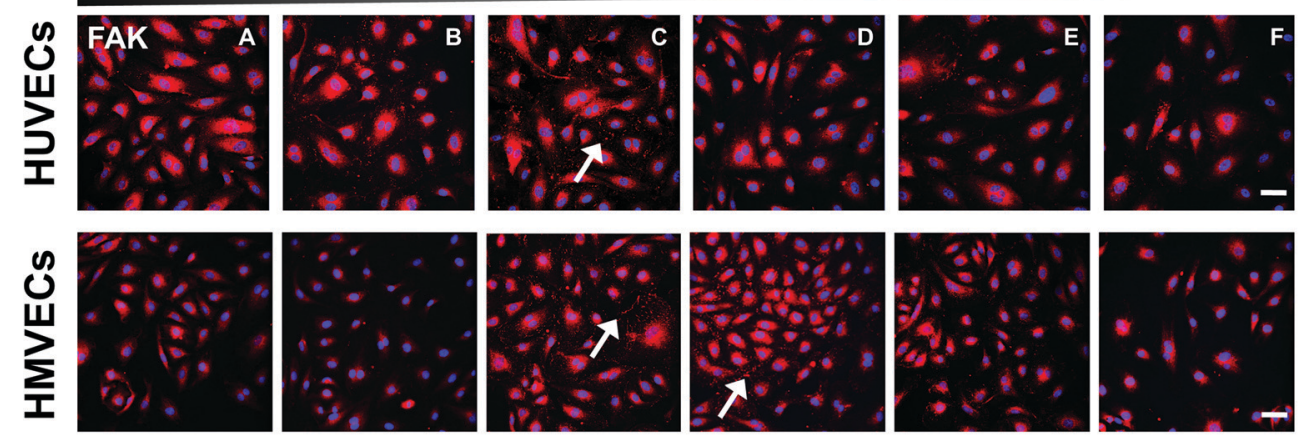

d
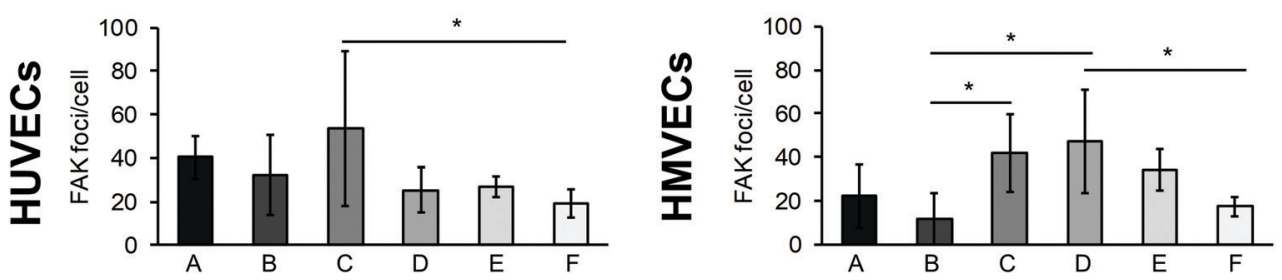

Fig. 7 Endothelial cell-to-cell junction variation on the different fibronectin-coated surfaces for both HUVECS and HMVECs. (a) VE-cadherin immunofluorescence staining of HUVECs (upper row) and HMVECs (lower row) on the different hydrophilic surfaces coated with FN. Scale bars equal $100 \mu \mathrm{m}$. (b) Semi-quantitative analysis of the anti-VE-cadherin-stained area for HUVECs (left) and HMVECs (right). Data is shown relative to surface F. (c) PECAM-1 immunofluorescence staining of HUVECs and HMVECs on the FN-coated surfaces. Scale bars equal $100 \mu \mathrm{m}$. (d) Semi-quantitative analysis of the anti-PECAM-1-stained area for HUVECs (left) and HMVECs (right). Data is shown relative to surface F. One-way ANOVA, $n=3,{ }^{\star} p<0.05,{ }^{* *} p<0.01$.

and D. To test this hypothesis, the adsorption of FN was further examined with fluorescence-labeled FN as well as with polyclonal and monoclonal antibody IF staining.

The total amount of adsorbed FN was determined with fluorescence-labeled FN. Here, the measured fluorescence intensity of the covalently labeled FN is directly proportional to the amount of adsorbed FN. This is, because the fluorescence DY-490 FN labeling took place prior to the adsorption. Compared to the antibody staining, the fluorescence signal is not affected by the protein adsorption and the associated changes in protein conformation and orientation. As we had a mean number of 2.6 dye molecules per FN, we do not expect that our labeling impaired the function and adsorption behavior of FN. A study by Hoffmann et al. analyzed the influence of FITC (a dye that is chemically related to DY-490) when covalently binding it to FN. For three dye molecules per FN, they could not detect significant modifications to the structure and biological function compared with unlabeled $\mathrm{FN}^{.}{ }^{53}$ Especially for surface A and F, the amount of coated FN was significantly higher when compared with the other surfaces. While for surface A the surface roughness probably allowed an increased FN adsorption, the amount of adsorbed FN on surface $\mathrm{F}$ was influenced by the material-driven FN fibrillogenesis, where the FN molecules were probably adsorbed in several layers. ${ }^{54,55}$ 
a

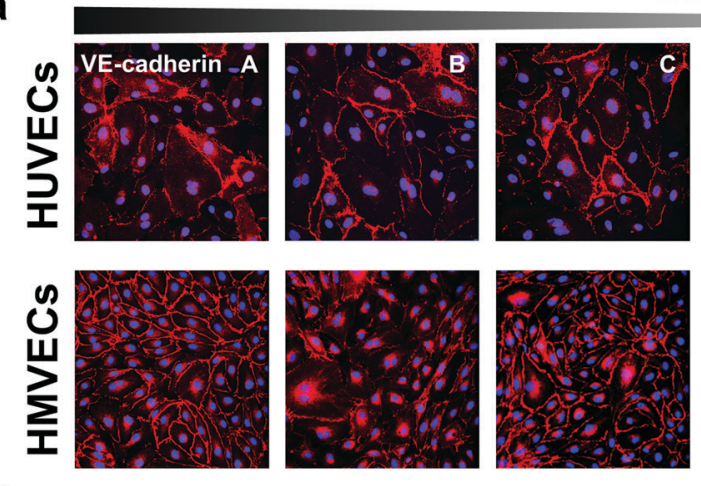

Wettability

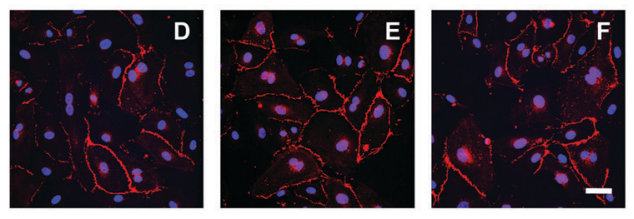

b
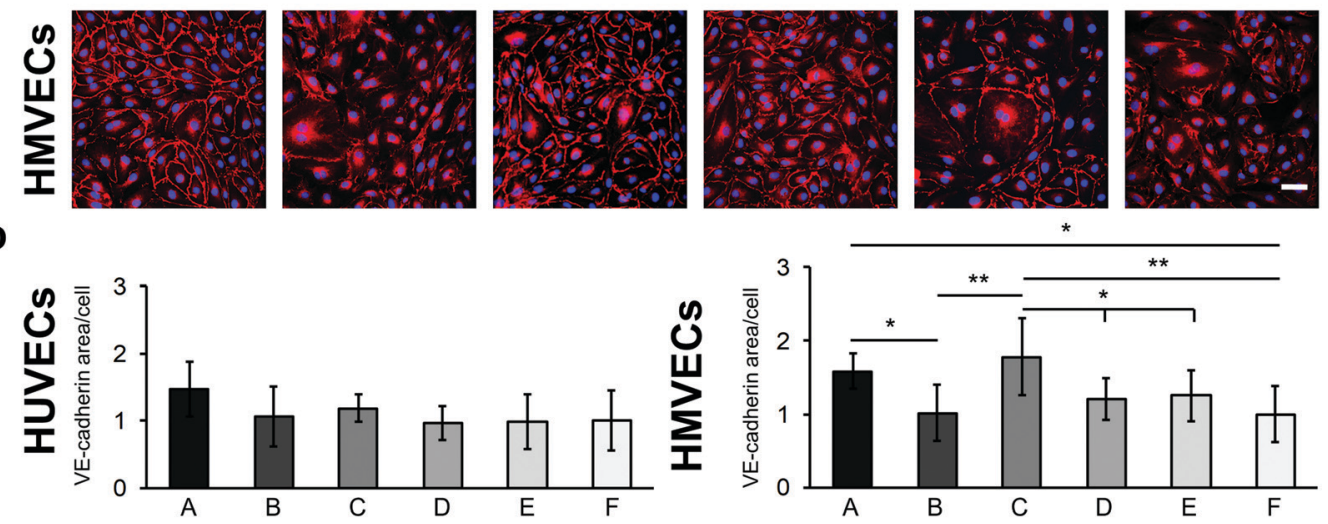

C

Wettability
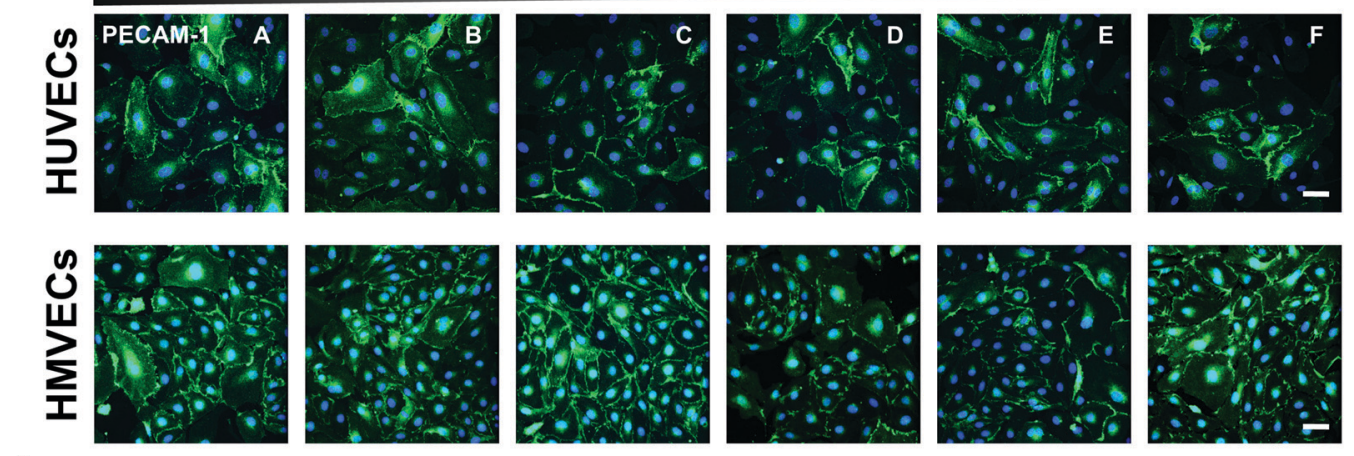

d
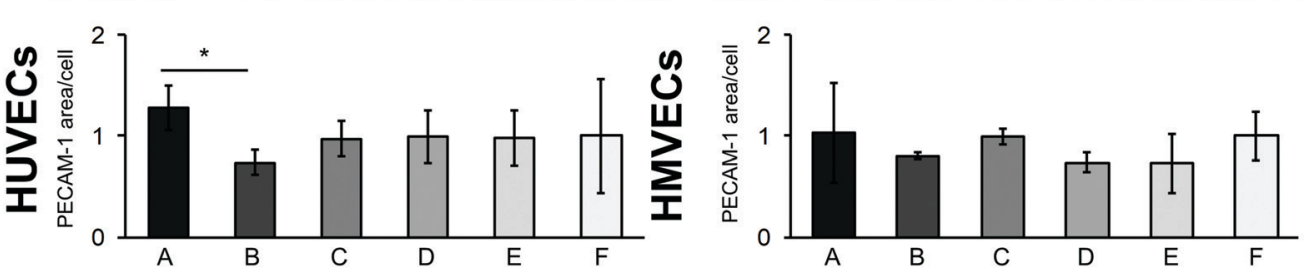

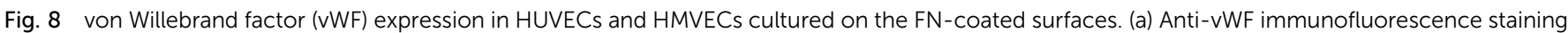

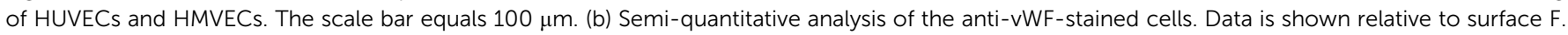
One-way ANOVA, $n=3,{ }^{*} p<0.05$.

The ratio of the amount of bound monoclonal and polyclonal anti-FN antibodies to the total amount of adsorbed fluorescence-labeled FN provides information about the conformation and orientation of the adsorbed protein. In our study, the individual surfaces showed different ratios, which indicates a varying adsorption behavior of FN on the surfaces (Fig. 3e and f). Since the polyclonal antibody binds to many different epitopes of $\mathrm{FN}$, we hypothesize that the lower the antibody signal, the more the conformation of the protein is altered and thus fewer epitopes are present or accessible to the antibody. Interestingly, there seems to be a reciprocal correlation between the results of the polyclonal antibody staining and the $k_{\mathrm{a}}$ values of the RIfS measurements (Fig. 3). Since the $k_{\mathrm{a}}$ value indirectly indicates the strength of the interaction between protein and surface, a greater conformational change can be assumed with stronger FN-material interaction. ${ }^{56}$ Thus, the results of the polyclonal antibody support the observations of the RIfS measurements, which indicates a slight conformational change of the $\mathrm{FN}$ on the surfaces $\mathrm{B}, \mathrm{C}$ and $\mathrm{D}$, and a stronger FN unfolding and expansion on the surfaces $\mathrm{E}$ and $\mathrm{F}$. This observation is consistent with the results of several studies that have described more drastic conformational changes on more hydrophobic surfaces. ${ }^{14,57}$ Interestingly, despite their hydrophilic properties, conformational changes of the protein also occurred on the surface A. We assume that the surface roughness caused by oxygen plasma treatment influenced the 
conformational change of the protein. Several studies have already described that surface roughness can lead to a widespread and rigid protein conformation. ${ }^{13,58}$

An additional indication of the conformational change of the adsorbed FN was provided by the results of the monoclonal HFN7.1 antibody, which binds near the cell binding domain consisting of the PHSRN and RGD integrin binding sites. ${ }^{33}$ In literature, an increased HFN7.1 antibody binding to unfolded FN has been described. ${ }^{14,59}$ In our study, especially samples A and D showed a high level of accessible cell binding domain indicating an extended FN conformation. However, our data suggest that the accessibility of the cell-binding-domain is not necessary and is solely associated with the conformational change, but also with the orientation of the protein. The FN adsorbed on surface D suggested only small conformational changes, but nevertheless showed a high availability of the cell binding domain. In contrast, the data for surface $\mathrm{F}$ indicates a more unfolded adsorbed protein, but with a low-exposed cell binding domain (Fig. 3b, e and f). From this we can conclude that depending on the surface properties, the adsorbed FN can take a more or less favorable conformation and orientation with respect to the accessibility of the cell binding domain, which ultimately influences its bioactivity. Since the surface chemistry and roughness of the surfaces C, D and E are similar, the difference in FN adsorption behavior on sample D could not be explained from the gathered information. Protein adsorption onto biomaterial surfaces is affected by many additional factors such as the stiffness, which have not been investigated. ${ }^{60}$ Methods such as fluorescence resonance energy transfer could be helpful to obtain further details about the conformation of the adsorbed FN.

Bridging these results to later applications, the key question of how these differences influence cell behavior was studied. For both HUVECs and HMVECs we found the same trend of differences in the number of adherent cells on the different surfaces. It should be noted that the cells were examined 24 hours after seeding. Thus, the cell count is not only determined by the number of initially attached cells but also by cell proliferation. Interestingly, our results show that the number of adherent cells does neither correlate with the amount of the exposed FN cell binding side nor with the wettability or polarity of the underlying surface. Rather, a correlation between the $k_{\mathrm{a}}$ value of the RIfS measurements and the cell count is observed (Fig. 3 and 4). We hypothesize that due to the stronger interaction with the surface and the resulting conformational change of the $\mathrm{FN}$, certain domains are exposed, which influence the cell cycle. In the literature it is described that binding to the first type III repeat or the heparin binding site of FN inhibits endothelial cell growth. ${ }^{61,62}$ It is also possible that a phenomenon described by Podestá et al. took place. ${ }^{63}$ In their study, the authors observed a decreased endothelial cell proliferation due to a reorganization of the cytoskeleton into actin filament bundles, which was induced by an increased density of focal contacts. Reduced cell growth associated with cytoskeletal reorganization may also be related to the CaMKK2/AMPK signaling pathway. It is described that the activation of AMPK leads to the maturation of contractile actomyosin bundles and causes cell cycle arrest. ${ }^{64-66}$ In our study, a reduced cell number was observed for both cell types on surfaces A and F, accompanied by the formation of actin bundles and an increased density of vinculin foci. This cytoskeletal organization indicates a resting endothelium, while stress fibers, as observed on surfaces B, C, D and E, occur when the endothelium is activated, a condition associated with cell proliferation and migration. ${ }^{67}$

During cell-FN interaction, which is mainly mediated by the integrins $\alpha 5 \beta 1$ and $\alpha v \beta 3$, focal adhesions are formed. ${ }^{68}$ On surfaces A and F, we think that the more unfolded conformation of FN, associated with an increased presentation of the cell binding side, facilitates the formation of mature focal adhesions composed of vinculin and $\alpha v \beta 3 .{ }^{69-71}$ In addition, a stronger FNmaterial interaction, as found on surface A, causes proper transmission of force through the actin cytoskeleton, allowing the maturation of vinculin-associated focal adhesions. ${ }^{72}$

Probably due to the stronger adhesion of the FN to the surface A, the cells can also form FN fibrils and develop actin bundles. ${ }^{67}$ It should be noted that the increased surface roughness of sample A to the other plasma treated samples can also influence the cell behavior. ${ }^{73}$

The more compact form of the FN molecule, which is assumed to be found on surfaces B, C and D, is only available for binding to $\alpha 5 \beta 1$ and not to $\alpha v \beta 3 .{ }^{74}$ Interestingly, higher levels of FAK foci, which are linked to integrin $\beta 1$, were usually found on these surfaces. ${ }^{75}$ The higher cell count and pronounced stress fibers in the cells on these surfaces can be attributed to FAK, as it enhances cell proliferation and cell motility by stimulating the formation of actin stress fibers and promoting the turnover of integrin-based adhesions. ${ }^{76-78}$ In addition, the potentially weaker FN-material interaction on these surfaces hinder the cells to form vinculin-rich mature focal adhesions. Instead, when the cells exert a traction force on the FN, they detach it from the surface, which is indicated by the dark areas on the anti-FN-stained surfaces ${ }^{79}$ (Fig. 4).

In our study, the expression of the endothelial cell markers vWF, VE-cadherin, and PECAM-1 was confirmed for both cell types. With regard to the formation of a functional endothelium on the FN-coated surfaces, the cell-to-cell junctions that establish the endothelial permeability barrier play an important role. $^{43}$ The slightly increased VE-cadherin and PECAM-1 expression in both cell types on surface A and for the HMVECs on surface $\mathrm{C}$ may indicate a more advanced formation of a functional endothelium compared to the other samples.

\section{Conclusion}

In our study, we showed that oxygen plasma treatment of PU surfaces through minor parameter changes induced large variations in the affinity, conformation and orientation of adsorbed FN, which in turn, significantly influenced the endothelial cell-material and cell-cell interactions. Due to the many simultaneous effects of plasma treatment on the surface 
through the introduction of a variety of functional groups and changes in surface topography, a direct link between a single parameter to the bioactivity of adsorbed $\mathrm{FN}$ or on the cell behavior could not be established; however, it was demonstrated that oxygen plasma treatment is a reliable, fast and reproducible technique with a high application potential in the adjustment of FN bioactivity and subsequent endothelial cell response.

\section{Source of funding}

This research was funded by the Deutsche Forschungsgemeinschaft (SCHE701/14-1 to K. S.-L.) and by the doctoral program of the University of Tübingen and Reutlingen University "Intelligente Prozess- und Materialentwicklung in der Biomateriomics (IPMB)" that is supported by the MWK BadenWürttemberg (to R. D., I. M., J. H. and A. J.).

\section{Conflicts of interest}

None.

\section{Acknowledgements}

The authors are grateful to Elke Nadler (University of Tübingen) for scientific advice and Julia Senz (University of Tübingen) for the contact angle measurements. We thank Shannon Lee Layland (University of Tübingen) for his valuable input and support with the final revisions. This research was funded by the Deutsche Forschungsgemeinschaft (SCHE701/14-1 to K.S.-L.) and by the joint doctoral program of the University of Tübingen and Reutlingen University "Intelligente Prozess- und Materialentwicklung in der Biomateriomics (IPMB)" that is financially supported by the MWK Baden-Württemberg (to R.D., I.M., J.H. and A.J.).

\section{References}

1 V. Llopis-Hernández, P. Rico, J. Ballester-Beltrán, D. Moratal and M. Salmerón-Sánchez, PLoS One, 2011, 6, e19610.

2 J. M. Seeger and N. Klingman, J. Vasc. Surg., 1988, 8, 476-482.

3 W. S. Choi, Y. K. Joung, Y. Lee, J. W. Bae, H. K. Park, Y. H. Park, J.-C. Park and K. D. Park, ACS Appl. Mater. Interfaces, 2016, 8, 4336-4346.

4 R. Daum, D. Visser, C. Wild, L. Kutuzova, M. Schneider, G. Lorenz, M. Weiss, S. Hinderer, U. A. Stock, M. Seifert and K. Schenke-Layland, Cells, 2020, 9, 778.

5 J. Zhu and R. A. F. Clark, J. Invest. Dermatol., 2014, 134, 895-901.

6 B. Geiger, A. Bershadsky, R. Pankov and K. M. Yamada, Nat. Rev. Mol. Cell Biol., 2001, 2, 793-805.

7 T. P. Ugarova, C. Zamarron, Y. Veklich, R. D. Bowditch, M. H. Ginsberg, J. W. Weisel and E. F. Plow, Biochemistry, 1995, 34, 4457-4466.
8 R. Mezzenga and M. Mitsi, Biomacromolecules, 2019, 20, 55-72.

9 R. Pankov and K. M. Yamada, J. Cell Sci., 2002, 115, 3861-3863.

10 W. S. To and K. S. Midwood, Fibrog. Tissue Repair, 2011, 4, 21.

11 M. Cantini, P. Rico, D. Moratal and M. Salmerón-Sánchez, Soft Matter, 2012, 8, 5575-5584.

12 P. Thevenot, W. Hu and L. Tang, Curr. Top. Med. Chem., 2008, 8, 270-280.

13 M. B. Hovgaard, K. Rechendorff, J. Chevallier, M. Foss and F. Besenbacher, J. Phys. Chem. B, 2008, 112, 8241-8249.

14 A. J. García, M. D. Vega and D. Boettiger, Mol. Biol. Cell, 1999, 10, 785-798.

15 B. G. Keselowsky, D. M. Collard and A. J. García, J. Biomed. Mater. Res., Part A, 2003, 66, 247-259.

16 A. J. Campillo-Fernández, R. E. Unger, K. Peters, S. Halstenberg, M. Santos, M. S. Sánchez, J. M. M. Dueñas, M. M. Pradas, J. L. G. Ribelles and C. J. Kirkpatrick, Tissue Eng., Part A, 2009, 15, 1331-1341.

17 F. A. Vanterpool, M. Cantini, F. P. Seib and M. SalmerónSánchez, BioRes. Open Access, 2014, 3, 286-296.

18 E. Grigoriou, M. Cantini, M. J. Dalby, A. Petersen and M. Salmeron-Sanchez, Biomater. Sci., 2017, 5, 1326-1333.

19 V. Llopis-Hernández, M. Cantini, C. González-García, Z. A. Cheng, J. Yang, P. M. Tsimbouri, A. J. García, M. J. Dalby and M. Salmerón-Sánchez, Sci. Adv., 2016, 2, E1600188.

20 C. González-García, M. Cantini, J. Ballester-Beltrán, G. Altankov and M. Salmerón-Sánchez, Acta Biomater., 2018, 77, 74-84.

21 K. M. Yamada and D. W. Kennedy, J. Cell Biol., 1984, 99, 29-36.

22 M. D. Pierschbacher, E. G. Hayman and E. Ruoslahti, J. Cell. Biochem., 1985, 28, 115-126.

23 S. I. Aota, M. Nomizu and K. M. Yamada, J. Biol. Chem., 1994, 269, 24756-24761.

24 P. Singh, C. Carraher and J. E. Schwarzbauer, Annu. Rev. Cell Dev. Biol., 2010, 26, 397-419.

25 I. Mrsic, T. Bäuerle, S. Ulitzsch, G. Lorenz, K. Rebner, A. Kandelbauer and T. Chassé, Appl. Surf. Sci., 2021, 536, 147782.

26 P. Alves, S. Pinto, H. C. de Sousa and M. H. Gil, J. Appl. Polym. Sci., 2011, 122, 2302-2308.

27 O. Mrad, J. Saunier, C. Aymes-Chodur, V. Rosilio, S. Bouttier, F. Agnely, P. Aubert, J. Vigneron, A. Etcheberry and N. Yagoubi, Microscopy and Microanalysis, Cambridge University Press, 2010, vol. 16, pp. 764-778.

28 M. Griffin, R. Palgrave, V. G. Baldovino-Medrano, P. E. Butler and D. M. Kalaskar, Int. J. Nanomed., 2018, 13, 6123-6141.

29 R. Hesse, T. Chassé, P. Streubel and R. Szargan, Surf. Interface Anal., 2004, 36, 1373-1383.

30 D. Nečas and P. Klapetek, Cent. Eur. J. Phys., 2012, 10, 181-188. 31 G. Kraus and G. Gauglitz, Fresenius' J. Anal. Chem., 1994, 349, 399-402. 
32 D. J. O'Shannessy, M. Brigham-Burke, K. Karl Soneson, P. Hensley and I. Brooks, Anal. Biochem., 1993, 212, 457-468.

33 R. Bowditch, C. Halloran, S. Aota, M. Obara, E. Plow, K. Yamada and M. Ginsberg, J. Biol. Chem., 1991, 266, 23323-23328.

34 E. Brauchle, J. Kasper, R. Daum, N. Schierbaum, C. Falch, A. Kirschniak, T. E. Schäffer and K. Schenke-Layland, Matrix Biol., 2018, 68-69, 180-193.

35 J. Pusch, M. Votteler, S. Göhler, J. Engl, M. Hampel, H. Walles and K. Schenke-Layland, Biomaterials, 2011, 32, 7469-7478.

36 A. Zbinden, M. Urbanczyk, S. L. Layland, L. Becker, J. Marzi, M. Bosch, P. Loskill, G. P. Duffy and K. Schenke-Layland, Tissue Eng., Part A, DOI: 10.1089/ten.tea.2020.0250.

37 J. Schindelin, I. Arganda-Carreras, E. Frise, V. Kaynig, M. Longair, T. Pietzsch, S. Preibisch, C. Rueden, S. Saalfeld, B. Schmid, J. Y. Tinevez, D. J. White, V. Hartenstein, K. Eliceiri, P. Tomancak and A. Cardona, Nat. Methods, 2012, 9, 676-682.

38 J. Ballester-Beltrán, P. Rico, D. Moratal, W. Song, J. F. Mano and M. Salmerón-Sánchez, Soft Matter, 2011, 7, 10803-10811.

39 N. V. Bogatcheva and A. D. Verin, Microvasc. Res., 2008, 76, 202-207.

40 C. Wu, Cell Adhes. Migr., 2007, 1, 13-18.

41 E. Spanjaard and J. De Rooij, Curr. Biol., 2013, 23.

42 X. Zhao and J. L. Guan, Adv. Drug Delivery Rev., 2011, 63, 610-615.

43 M. G. Lampugnani, Cold Spring Harbor Perspect. Med., 2012, 2, a006528.

44 J. Friedrich, The Plasma Chemistry of Polymer Surfaces, WileyVCH Verlag GmbH \& Co. KGaA, Weinheim, Germany, 2012.

45 B. Mutel, M. Bigan and H. Vezin, Appl. Surf. Sci., 2004, 239, 25-35.

46 L. Yang, J. Chen, Y. Guo and Z. Zhang, Appl. Surf. Sci., 2009, 255, 4446-4451.

47 F. Arefi-Khonsari, M. Tatoulian, F. Bretagnol, O. Bouloussa and F. Rondelez, Surf. Coatings Technol., 2005, 200, 14-20.

48 J. Lai, B. Sunderland, J. Xue, S. Yan, W. Zhao, M. Folkard, B. D. Michael and Y. Wang, Appl. Surf. Sci., 2006, 252, 3375-3379.

49 N. Inagaki, K. Narushim, N. Tuchida and K. Miyazaki, J. Polym. Sci., Part B: Polym. Phys., 2004, 42, 3727-3740.

50 R. N. Wenzel, J. Phys. Colloid Chem., 1949, 53, 1466-1467.

51 M. Salmerón-Sánchez, P. Rico, D. Moratal, T. T. Lee, J. E. Schwarzbauer and A. J. García, Biomaterials, 2011, 32, 2099-2105.

52 R. A. Latour, J. Biomed. Mater. Res., Part A, 2015, 103, 949-958.

53 C. Hoffmann, J. Leroy-Dudal, S. Patel, O. Gallet and E. Pauthe, Anal. Biochem., 2008, 372, 62-71.

54 D. Khang, S. Y. Kim, P. Liu-Snyder, G. T. R. Palmore, S. M. Durbin and T. J. Webster, Biomaterials, 2007, 28, 4756-4768.

55 Y. Zhang, C. Chai, X. S. Jiang, S. H. Teoh and K. W. Leong, Mater. Sci. Eng., C, 2007, 27, 213-219.

56 P. Roach, D. Farrar and C. C. Perry, J. Am. Chem. Soc., 2005, 127, 8168-8173.

57 V. Vadillo-Rodríguez, M. A. Pacha-Olivenza, M. L. GónzalezMartín, J. M. Bruque and A. M. Gallardo-Moreno, J. Biomed. Mater. Res., Part A, 2013, 101A, 1397-1404.
58 M. S. Lord, B. G. Cousins, P. J. Doherty, J. M. Whitelock, A. Simmons, R. L. Williams and B. K. Milthorpe, Biomaterials, 2006, 27, 4856-4862.

59 D. Gagné, Y. D. Benoit, J. F. Groulx, P. H. Vachon and J. F. Beaulieu, BMC Mol. Cell Biol., 2020, 21, 14.

60 N. B. Guerra, C. González-García, V. Llopis, J. C. RodríguezHernández, D. Moratal, P. Rico and M. Salmerón-Sánchez, Soft Matter, 2010, 6, 4748-4755.

61 A. Ambesi, R. M. Klein, K. M. Pumiglia and P. J. McKeownLongo, Cancer Res., 2005, 65, 148-156.

62 G. A. Homandberg, J. Kramer-Bjerke, D. Grant, G. Christianson and R. Eisenstein, Biochim. Biophys. Acta, Protein Struct. Mol. Enzymol., 1986, 874, 61-71.

63 F. Podestá, T. Roth, F. Ferrara, E. Cagliero and M. Lorenzi, Diabetologia, 1997, 40, 879-886.

64 L. Miranda, S. Carpentier, A. Platek, N. Hussain, M. A. Gueuning, D. Vertommen, Y. Ozkan, B. Sid, L. Hue, P. J. Courtoy, M. H. Rider and S. Horman, Biochem. Biophys. Res. Commun., 2010, 396, 656-661.

65 S. Fogarty, F. A. Ross, D. V. Ciruelos, A. Gray, G. J. Gowans and D. G. Hardie, Mol. Cancer Res., 2016, 14, 683-695.

66 S. Tojkander, K. Ciuba and P. Lappalainen, Cell Rep., 2018, 24, 11-19.

67 H. Schnittler, M. Taha, M. O. Schnittler, A. A. Taha, N. Lindemann and J. Seebach, Cell Tissue Res., 2014, 355, 529-543.

68 E. H. J. Danen, P. Sonneveld, C. Brakebusch, R. Fässler and A. Sonnenberg, J. Cell Biol., 2002, 159, 1071-1086.

69 J. L. Coll, A. Ben-Ze'ev, R. M. Ezzell, J. L. Rodríguez Fernández, H. Baribault, R. G. Oshima and E. D. Adamson, Proc. Natl. Acad. Sci. U. S. A., 1995, 92, 9161-9165.

70 R. M. Saunders, M. R. Holt, L. Jennings, D. H. Sutton, I. L. Barsukov, A. Bobkov, R. C. Liddington, E. A. Adamson, G. A. Dunn and D. R. Critchley, Eur. J. Cell Biol., 2006, 85, 487-500.

71 V. Schaufler, H. Czichos-Medda, V. Hirschfeld-Warnecken, S. Neubauer, F. Rechenmacher, R. Medda, H. Kessler, B. Geiger, J. P. Spatz and E. A. Cavalcanti-Adam, Cell Adhes. Migr., 2016, 10, 505-515.

72 A. Sales, K. Ende, J. Diemer, A. R. Kyvik, J. Veciana, I. Ratera, R. Kemkemer, J. P. Spatz and J. Guasch, ACS Omega, 2019, 4, 1791-1800.

73 H. Amani, H. Arzaghi, M. Bayandori, A. S. Dezfuli, H. Pazoki-Toroudi, A. Shafiee and L. Moradi, Adv. Mater. Interfaces, 2019, 6, 1900572.

74 S. Huveneers, H. Truong, R. Fässler, A. Sonnenberg and E. H. J. Danen, J. Cell Sci., 2008, 121, 2452-2462.

75 X. K. Zhao, Y. Cheng, M. Liang Cheng, L. Yu, M. Mu, H. Li, Y. Liu, B. Zhang, Y. Yao, H. Guo, R. Wang and Q. Zhang, Sci. Rep., 2016, 6, 1-12.

76 A. P. Gilmore and L. H. Romer, Mol. Biol. Cell, 1996, 7, 1209-1224.

77 K. Katoh, PeerJ, 2017, 2017, e4063.

78 C. Lawson and D. D. Schlaepfer, Cell Adhes. Migr., 2012, 6, 302-306.

79 D. K. Pettit, T. A. Horbett and A. S. Hoffman, J. Biomed. Mater. Res., 1992, 26, 1259-1275. 